\title{
Abiotic stress protection by ecologically abundant dimethylsulfoniopropionate and its natural and synthetic derivatives: insights from Bacillus subtilis
}

\author{
Broy Sebastian ${ }^{1}$, Chen Chiliang ${ }^{1,2}$, Hoffmann Tamara ${ }^{1,2}$, Brock Nelson L. ${ }^{3}$, Nau-Wagner Gabriele ${ }^{1}$, \\ Jebbar Mohamed ${ }^{1,4,7}$, Smits Sander H. J. ${ }^{5}$, Dickschat Jeroen S. ${ }^{3,6}$, Bremer Erhard ${ }^{1,2,{ }^{*}}$
}

${ }^{1}$ Laboratory for Microbiology; Department of Biology; Philipps-University Marburg; Karl-von-Frisch Str. 8 D-35043 Marburg Germany

${ }^{2}$ LOEWE-Center for Synthetic Microbiology; Philipps-University Marburg; Hans-Meerwein Str. D-35043 Marburg Germany

${ }^{3}$ Institute of Organic Chemistry; Technical University of Braunschweig; Hagenring 30 D-38106 Braunschweig Germany

${ }^{4}$ Laboratory of Microbiology of Extreme Environments; UMR 6197 (CNRS - Ifremer - UBO); European Institute of Marine Studies; University of West Brittany (Brest); Technopole Brest-Iroise F-29280 Plouzané France

${ }^{5}$ Institute of Biochemistry; Heinrich-Heine-University Düsseldorf; Universitäts Str. 1 D-40225 Düsseldorf Germany

${ }^{6}$ Kekule-Institute for Organic Chemistry and Biochemistry; Friedrich Wilhelms-University Bonn; Gerhard-Domagk-Str. 1 D-53121 Bonn Germany

${ }^{7}$ Ifremer, France

* Corresponding author : Erhard Bremer, Tel. (+49) 64212821529 ; Fax (+49) 64212828979 ;

email address : bremer@biologie.uni-marburg.de

\begin{abstract}
:
Dimethylsulfoniopropionate (DMSP) is an abundant osmolyte and anti-stress compound produced primarily in marine ecosystems. After its release into the environment, microorganisms can exploit DMSP as a source of sulfur and carbon, or accumulate it as an osmoprotectant. However, import systems for this ecophysiologically important compatible solute, and its stress-protective properties for microorganisms that do not produce it are insufficiently understood. Here we address these questions using a well-characterized set of Bacillus subtilis mutants to chemically profile the influence of DMSP import on stress resistance, the osmostress-adaptive proline pool and on osmotically controlled gene expression. We included in this study the naturally occurring selenium analogue of DMSP, dimethylseleniopropionate (DMSeP), as well as a set of synthetic DMSP derivatives. We found that DMSP is not a nutrient for B. subtilis, but it serves as an excellent stress protectant against challenges conferred by sustained high salinity or lasting extremes in both low and high growth temperatures. DMSeP and synthetic DMSP derivatives retain part of these stress protective attributes, but DMSP is clearly the more effective stress protectant. We identified the promiscuous and widely distributed $A B C$ transporter OpuC as a high-affinity uptake system not only for DMSP, but also for its natural and synthetic derivatives.
\end{abstract}




\section{Introduction}

The tertiary sulfonium compound dimethylsulfoniopropionate (DMSP) (Fig. 1) is an integral constituent of the global sulfur cycle operating on our planet (Charlson et al., 1987; Kiene et al., 2000). It is produced in vast amounts (about $10^{9}$ tons annually) by marine phytoplankton and macroalgae and also by a restricted number of plants that typically populate ecosystems near the sea (Yoch, 2002; Otte et al., 2004; Curson et al., 2011a; Reisch et al., 2011; Moran et al., 2012). These organisms can attain high intracellular concentrations of DMSP through synthesis (up to $400 \mathrm{mM}$ ) (Stefels, 2000) and upon cell lysis (e.g., after attack by grazing zooplankton and viruses) or osmotic down-shock, release it into open ocean waters, estuarine ecosystems and sediments. In these natural habitats, DMSP can be found in nM or low $\mu \mathrm{M}$ concentrations (Kiene et al., 1998; Van Duyl et al., 1998; Vila-Costa et al., 2006). Microorganisms can then take advantage of environmental DMSP either as a stress protectant (Welsh, 2000), or as a nutrient (Curson et al., 2011b; Rinta-Kanto et al., 2011; Levine et al., 2012; Rinta-Kanto et al., 2012; Todd et al., 2012).

Evidence for several ecophysiological functions of DMSP has been provided. It is considered to act as an antioxidant, as a cryoprotectant, as a chemical cue in the grazing interactions between zooplankton and phytoplankton and as a chemo-attractant for DMSP-consuming bacteria in their relations with the corresponding DMSP-producing dinoflagellate (Karsten et al., 1992; Wolfe et al., 1997; Bayles and Wilkinson, 2000; Sunda et al., 2002; Miller et al., 2004). It is, however, best known for its role as an osmolyte for the producer organisms (Stefels, 2000), most of which live in highsaline environments (Yoch, 2002; Curson et al., 2011a; Reisch et al., 2011; Moran et al., 2012). Notably, osmostress protection by DMSP can also be conferred through its uptake by microorganisms that do not produce it (Gouesbet et al., 1994; Pichereau et al., 1998; Cosquer et al., 1999; Bayles and Wilkinson, 2000; Murdock et al., 2014).

DMSP is a zwitter-ion with no net charge at physiological $\mathrm{pH}$ and a member of a selected class of highly water-soluble organic osmolytes, the compatible solutes. Members of all three domains of life exploit these types of compounds to offset the detrimental effects of high salinity and high osmolarity on cellular water content, volume, and physiology (Kempf and Bremer, 1998; Roeßler and Müller, 2001; Yancey, 2005). However, the beneficial effects of compatible solutes extend beyond 
their well-established role in osmoregulation, as they also serve as stabilizers of proteins, improve their solubility and preserve the functionality of cell components or even of entire cells (Lippert and Galinski, 1992; Bourot et al., 2000; Manzanera et al., 2002; Ignatova and Gierasch, 2006; Street et al., 2010; Auton et al., 2011). The term chemical chaperone has been coined in the literature to reflect these beneficial traits (Diamant et al., 2001).

Bacteria can derive protection against abiotic stress both through synthesis and uptake of compatible solutes (Kempf and Bremer, 1998; Bremer and Krämer, 2000). A microorganism in which these processes are well characterized, both at the physiological and at the molecular level is the ubiquitously distributed Gram-positive bacterium Bacillus subtilis (Bremer, 2002). Upon a high osmolarity challenge, $B$. subtilis produces very large amounts of the compatible solute proline as a cell protectant (Whatmore et al., 1990; Brill et al., 2011; Hoffmann et al., 2013). This bacterium has also been shown to attain relief from sustained osmostress through the import of different types of compatible solutes, most of which are chemically related to either glycine betaine or proline (von Blohn et al., 1997; Bremer, 2002; Hoffmann and Bremer, 2011; Bashir et al., 2014b; Bashir et al., 2014a). The uptake of compatible solutes by $B$. subtilis is mediated via a set of osmotically inducible uptake systems, the Opu family of transporters (Bremer, 2002). These transporters also serve for the import of compatible solutes when they are used as protectants against extremes in either low or high growth temperatures (Holtmann and Bremer, 2004; Hoffmann and Bremer, 2011; Bashir et al., 2014b; Bashir et al., 2014a).

Members of the genus Bacillus can colonize a great variety of ecosystems (Earl et al., 2008; Logan and De Vos, 2009), including marine and estuarine habitats and sediments (Siefert et al., 2000; Miranda et al., 2008; Ettoumi et al., 2013). In these ecosystems, B. subtilis would certainly have access to the ecologically abundant DMSP but it is unknown whether it catabolizes DMSP and/or can derive stress protection from DMSP after its uptake. Here we address these ecologically important questions through the evaluation of DMSP, its natural selenium analogue dimethlyselenoniopropionate (DMSeP), its synthetic tellurium derivative dimethyltelluriopropionate (DMTeP), and five DMSPinspired synthetic compounds whose sulfonium head-groups have been extensively chemically modified (Fig. 1). 
103

104

105

106

107

108

109

110

111

112

113

114

115

116

117

\section{Results}

DMSP is not a nutrient for B. subtilis

Many microorganisms can catabolize DMSP (Curson et al., 2011a; Reisch et al., 2011; Moran et al., 2012). To test if $B$. subtilis could use it as sole carbon or sulfur source, cultures of the wild-type strain JH642 were grown in a chemically defined medium (SMM or SMM with $0.4 \mathrm{M} \mathrm{NaCl}$ ) in which glucose $(28 \mathrm{mM})$ was replaced with $33 \mathrm{mM}$ DMSP as the sole carbon source. No growth was observed after $20 \mathrm{~h}$ of incubation of the cultures (Fig. S1A). Likewise, no growth was observed when DMSP was offered to the cells as sole sulfur source $(15 \mathrm{mM})$ (Fig. S1B). Since DMSP can sometimes be toxic, we also tested a lower concentration ( $2 \mathrm{mM})$ of DMSP in our growth assays; no growth was observed under these conditions either (Fig. S1A and B). We therefore conclude that B. subtilis belongs to the group of microorganisms that cannot exploit DMSP as a nutrient.

Stress protection by DMSP and its derivatives against high salinity and extremes in growth temperature

We tested the stress-protective properties of DMSP, it natural selenium analogue dimethlyseleniopropionate (DMSeP) (Ansede and Yoch, 1997; Ansede et al., 1999), and six synthetic DMSP derivatives (Dickschat et al., 2010; Brock et al., 2014) (Fig. 1) for B. subtilis cells that were continuously challenged either by extremes in salinity $(1.2 \mathrm{M} \mathrm{NaCl})$ or growth temperatures $\left(13^{\circ} \mathrm{C}\right.$ and $52^{\circ} \mathrm{C}$ ). DMSP exerted the same level of osmostress protection as the highly effective compatible solute glycine betaine (Boch et al., 1994) (Fig. 2A). DMSeP was also a good osmostress protectant and was followed in its potency by the synthetic DMSP derivatives dimethyltelluriopropionate (DMTeP), ethylmethylsulfoniopropionate (EMSP), diethylsulfoniopropionate (DESP), isopropylmethylsulfoniopropionate (IMSP), and tetramethylenesulfoniopropionate (TMSP). In contrast, methylpropylsulfoniopropionate (MPSP) did not serve as an osmoprotectant for B. subtilis (Fig. 2A).

Many compatible solutes used by B. subtilis as osmoprotectants (Bremer, 2002) also protect cells against stress at the cutting edges of the temperature spectrum that $B$. subtilis cells can populate in a defined chemical medium (Holtmann and Bremer, 2004; Hoffmann and Bremer, 2011). DMSP 
131 resembled the established cold protectant glycine betaine in its ability to promote growth at $13^{\circ} \mathrm{C}$, a

132 temperature that otherwise severely restricts growth of B. subtilis (Hoffmann and Bremer, 2011) (Fig.

133 2B). The naturally occurring DMSeP and the synthetic EMSP also offered reasonably good cold stress

134 protection, while the remaining synthetic DMSP derivatives afforded either no protection or provided

135 cellular protection at a very low level (Fig. 2B).

136 When DMSP and its full set of derivatives were assayed for their heat stress protection

137 potential at a growth temperature of $52^{\circ} \mathrm{C}$, only DMSP provided thermoprotection to $B$. subtilis at a

138 level comparable to the established heat stress protectant glycine betaine (Holtmann and Bremer,

139 2004) (Fig. 2C).

140

Import of DMSP and its derivatives down-regulates the size of the osmostress-adaptive proline pool

142 The adaptation of $B$. subtilis to sustained high osmolarity growth conditions is afforded through the

143 biosynthesis and accumulation of large amounts of the compatible solute proline (Whatmore et al.,

144 1990; Brill et al., 2011). In this adjustment process, the intracellular proline concentration is

145 sensitively linked to the degree of the osmotic stress imposed by the environment onto the cell (Brill et

146 al., 2011; Hoffmann et al., 2013). Proline pools approaching or exceeding 0.5 M can be found when

147 the osmotic stress is severe (Hoffmann et al., 2013; Zaprasis et al., 2013). In turn, the import of

148 various kinds of osmoprotectants down-regulates the cellular proline content of high osmolarity

149 challenged cells in a finely tuned fashion and thereby allows the saving of precious energy sources and

150 biosynthetic building blocks for proline production (Akashi and Gojobori, 2002; Hoffmann et al.,

151 2013; Bashir et al., 2014b).

152 To test if DMSP and its various derivatives would exert similar dampening effects on the size

153 of the newly produced proline pool, we grew strain JH642 in SMM containing $1.2 \mathrm{M} \mathrm{NaCl}$ in the

154 absence or the presence of various concentrations of these compounds and measured the free proline

155 content of the cells. As observed previously (Hoffmann et al., 2013), the presence of glycine betaine in

156 the growth medium resulted in a significantly reduced intracellular proline pool as the glycine betaine

157 concentration in the medium was increased from $25 \mu \mathrm{M}$ to $1 \mathrm{mM}$ (Fig. 3). DMSP and DMSeP exerted 
158 a similar effect (Fig. 3). All other DMSP derivatives affected the proline pools more modestly, with

159 TMSP conferring an intermediate effect (Fig. 3).

160

DMSP and its derivatives reduce the level of opuA expression at high salinity

162 The import of glycine betaine by osmotically stressed cells not only allows to maintain a 163 physiologically appropriate level of cellular hydration (Cayley et al., 1992), but it also affects gene 164 expression in B. subtilis on a global scale (Kohlstedt et al., 2014). The activity of the promoter for the opuA operon is a good reporter for such effects, both because it is strongly induced by high osmolarity but also responsive to cellular pools of various compatible solutes built up through transport processes (Hoffmann et al., 2013; Bashir et al., 2014b; Bashir et al., 2014a). Strain MBB9 carries a chromosomal copy of an opuA-treA operon fusion that expresses this hybrid reporter gene under the control of the opuA promoter (Hoffmann et al., 2013). The level of the TreA reporter enzyme, a salt-tolerant phospho- $\alpha-(1,1)$-glucosidase (Gotsche and Dahl, 1995), can thus be used as a read-out for the assessment of the potential influence of DMSP and its derivatives on osmotically controlled gene expression. Cultures of strain MBB9 were grown in the absence or presence $(1 \mathrm{mM})$ of these solutes in SMM or in SMM containing $1.2 \mathrm{M} \mathrm{NaCl}$. In the absence of a

174 compatible solute in the growth medium, transcription of the opuA-treA reporter fusion was induced about 8.5 -fold when the external salinity was increased (Table 1). The osmoprotectants glycine betaine and carnitine (Boch et al., 1994; Kappes and Bremer, 1998) reduced the salt-induced level of opuA transcription about five- to six-fold and so did DMSP (Table 1). DMSP, glycine betaine and carnitine

178 also down-regulated (between 3.6 and 4-fold) the level of opuA-treA expression found in the absence 179 of added $\mathrm{NaCl}$ and thereby still permitted an osmotic up-regulation (between 4.9 and 6.6 -fold) in the 180 expression level of the reporter fusion (Table 1). The reduction in the level of opuA-treA transcription 181 by the DMSP selenium analogue DMSeP and the tested synthetic DMSP derivatives in salt-stressed 182 and non-stressed cells was less pronounced, between 1.5- and 2.5-fold under osmotic stress conditions 183 and between 1.7- and 3.5-fold in non-stressed cells (Table 1). 
186 The osmoprotective effect of an exogenous supply of compatible solutes depends on their import 187 (Kappes et al., 1996; Hoffmann et al., 2013). B. subtilis possesses five osmotically inducible uptake systems for these compounds, the Opu (osmoprotectant uptake) family of transporters which comprises both multi-component $\mathrm{ABC}$ transporters (OpuA, $\mathrm{OpuB}$ and $\mathrm{OpuC})$ and single component uptake systems that belong either to the MFS (OpuE) or to the BCCT (OpuD) super-families (Bremer, 2002). A comprehensive set of mutant strains is available, each expressing only one of these transport systems, while the genes for the other transporters have been deleted (Table 3) (Hoffmann and Bremer, 2011). These B. subtilis mutant strains thus allow a determination which transporter is used by a given osmoprotectants through a simple growth assay. When applied to DMSP and its natural and synthetic derivatives, we found that DMSP can confer osmostress protection in strains that possess either an intact OpuA or OpuC system, whereas all other DMSP derivatives were imported only via OpuC (Fig. 4). Consequently, in a strain with simultaneously defective OpuA and OpuC transporters, osmoprotection by DMSP and its derivatives was lost, while that afforded by glycine betaine remained (Fig. 4) since it can be imported not only via the $\mathrm{ABC}$ transporters OpuA and OpuC but also through the BCCT (betaine-carnitine-choline-transporter)-type transporter OpuD (Kappes et al., 1996; Ziegler et al., 2010).

We also tested the role of the individual Opu transporters for the import of DMSP and its derivatives under both cold- and heat-stress conditions. The same transporters used for the uptake of these solutes in salt-stressed cells were also used by cells exposed to either sustained cold $\left(13^{\circ} \mathrm{C}\right)$ (Fig. S2A) or sustained heat stress $\left(52^{\circ} \mathrm{C}\right)$ (Fig. S2B).

\section{Kinetic parameters of OpuA and OpuC for DMSP and its derivatives}

208 To study the uptake of DMSP and its derivatives by B. subtilis in more detail, competition assays with

209 DMSP and radiolabeled $\left[1-{ }^{14} \mathrm{C}\right]$ glycine betaine were conducted. We first studied the import of DMSP

210 via the OpuA ABC transporter in cells that were grown in the presence of $0.4 \mathrm{M} \mathrm{NaCl}$. Uptake of [1-

$211{ }^{14} \mathrm{C}$ ]glycine betaine exhibited Michaelis-Menten kinetics (Fig. 5A) and yielded a $K_{m}$ value of $3 \pm 1$

$212 \mu \mathrm{M}$, which agrees very well with a previous estimate of $2.4 \mu \mathrm{M}$ (Kappes et al., 1996). In contrast to 
213 the high-affinity import of glycine betaine by OpuA, uptake of DMSP was a low-affinity process and 214 yielded a $K_{i}$ value of $912 \pm 275 \mu \mathrm{M}$ (Fig. 5A).

215 Next, we studied the import of DMSP and its derivatives via the OpuC ABC transporter in 216 osmotically stressed cells (with $0.4 \mathrm{M} \mathrm{NaCl}$ ). Uptake of $\left[1-{ }^{14} \mathrm{C}\right]$ glycine betaine proceeded with high 217 affinity and yielded a $K_{m}$ of $7 \pm 1 \mu \mathrm{M}$ (Table 2 ), again a value that is in excellent agreement with a 218 previous report $\left(K_{m}: 6 \mu \mathrm{M}\right)$ (Kappes et al., 1996). OpuC-mediated import of DMSP was a high-affinity 219 process as well and yielded a $K_{i}$ value of $39 \pm 7 \mu \mathrm{M}$ (Fig. 5B). The transport characteristics of OpuC 220 for the uptake of six tested DMSP derivatives yielded similar $K_{i}$ values (Table 2), thereby identifying this transporter as a high affinity uptake system for DMSP and its natural and synthetic DMSP derivatives (Fig. 1). The details of the uptake characteristics of the studied DMSP derivatives are 223 documented in Fig. S3.

Uptake studies with $\left[1-{ }^{14} \mathrm{C}\right]$ glycine betaine in the presence of MPSP (Fig. 1) as a potential inhibitor of the OpuC-mediated transport process demonstrated that this synthetic DMSP derivative did not compete with glycine betaine import (Fig. S4). MPSP is the DMSP derivative to which we could not ascribe a biological function in B. subtilis (Fig. 2) and this can now be understood. However, it is not immediately evident why this particular DMSP derivative (Fig. 1) is not recognized as a substrate by the OpuC transporter.

In silico docking of DMSP into the ligand-binding sites of the OpuAC and OpuCC solute receptor proteins

233 The primary substrate recognition component of microbial binding-protein-dependent $\mathrm{ABC}$ 234 transporters are the extracellular solute receptor proteins of these systems (Berntsson et al., 2010). 235 OpuAC and OpuCC are the extracellular substrate binding proteins of the OpuA and OpuC ABC 236 transport systems (Kempf and Bremer, 1995; Kappes et al., 1999) and crystal structures of these 237 proteins in complex with various substrates have been reported (Horn et al., 2006; Smits et al., 2008; Du et al., 2011). Since no ligand binding protein associated with an ABC transport system has been crystalized in the presence of DMSP, we carried out in silico modeling studies to derive clues on the molecular determinants governing the binding of DMSP by the OpuAC and OpuCC proteins. We 
relied for these ligand-docking experiments on crystallographic data available for the OpuAC protein

242 in complex with the sulfur analog of glycine betaine, dimethlysulfonioacetate (DMSA; Fig. 1) (PDB code 3CHG) (Smits et al., 2008), and the OpuCC:glycine betaine complex (PDB code 3PPP) (Du et al., 2011) (Fig. 6). Crystallographic data relevant for the properties of the DMSP ligand were extracted from the structure of the DMSP lyase DddQ from Silicibacter lacuscaerulensis (PDB database entry 4LA2) (Li et al., 2014).

The OpuAC:DMSA complex (Smits et al., 2008) was chosen as the starting structure for the modeling since DMSP and DMSA are chemically closely related sulfur-containing molecules (Fig. 1). An aromatic ligand-binding cage in the OpuAC protein is formed by the side chains of three Trp 250 residues $\left(\operatorname{Trp}^{72}, \operatorname{Trp}^{178}\right.$ and $\left.\operatorname{Trp}^{225}\right)$ that are arranged in form of a prism (Horn et al., 2006). The 251 positively charged dimethylsulfonio head group of DMSA is accommodated within this aromatic 252 micro-environment via cation- $\pi$ interactions. Its carboxylate interacts via hydrogen bonds with the backbone nitrogens of $\mathrm{Gly}^{26}$ and $\mathrm{Ile}^{27}$ (Fig. 6). To derive a OpuAC:DMSP model, we first exchanged in silico the DMSA ligand in the OpuAC:DMSA complex by a DMSP molecule and then refined the resulting in silico-generated complex against the structure factors of the OpuAC:DMSA structure deposited in the PDB file 3CHG (Smits et al., 2008) to ensure the correctness of the bond length and angles of the DMSP ligand. As expected, our in silico model envisions that the positively charged dimethylsulfonio head group of the DMSP ligand is also accommodated by the above described aromatic cage via cation- $\pi$ interactions, but due to the increased length of the main carbon chain of the DMSP molecule by a $\mathrm{CH}_{2}$ group (Fig. 1), the position of the sulfur atom is slightly shifted (by about $0.7 \AA$ ) relative to that of the DMSA ligand. As a consequence of this shift, the carboxylate of DMSP is

262 still able to interact with the backbone nitrogens of $\mathrm{Gly}^{26}$ and $\mathrm{Il}^{27}$ in the OpuAC protein (Fig. 6), 263 interactions that are also found in the OpuAC:DMSA complex (Smits et al., 2008).

264 The reduced number of cation- $\pi$ and van der Waals interactions of the OpuAC:DMSA 265 complex in comparison with the OpuAC:glycine betaine crystal structure, decreases the binding of 266 DMSA by OpuAC relative to glycine betaine by five-fold; from a $K_{d}$ of about $20 \mu \mathrm{M}$ for glycine 267 betaine to a $K_{d}$ of about $100 \mu \mathrm{M}$ for DMSA (Smits et al., 2008). Given the low affinity of the OpuA 268 transporter for DMSP ( $K_{i}$ of about $1 \mathrm{mM}$ ) (Fig 5A), one must assume that the predicted shift in the 
269

270

271

272

273

274

275

276

277

278

279

280

281

282

283

284

285

286

287

288

289

290

291

292

293

294

295

296

position of the dimethylsulfonio head group of DMSP within the OpuAC ligand binding site (Fig. 6) is sub-optimal for the stability of the OpuAC:DMSP complex. Ligand binding by OpuAC is sensitive to slight variations. Even conservative amino acid substitutions in the aromatic cage by other aromatic residues that cause an altered geometry in the cation- $\pi$ interactions can have drastic consequences for the affinity of OpuAC for different ligands (Smits et al., 2008). The covalent radii for the S, Se and Te are $103 \mathrm{pm}, 117 \mathrm{pm}$ and $135 \mathrm{pm}$, respectively (Housecroft and Sharp, 2008). The resulting increasing bulkiness of the positively charged head-groups of DMSP, DMSeP, and TMSTeP (Fig. 1) is likely a contributor why the DMSeP and DMTeP molecules cannot be stably bound by the OpuAC solute receptor protein. As reflected by the high $K_{i}$ value of the OpuA transporter for DMSP (approximately $1 \mathrm{mM}$ ) (Fig. 5A), binding of DMSP by the OpuAC receptor protein is thus a borderline case.

Since no crystal structure of the OpuCC protein with a sulfur-betaine such as DMSA is available, we used the OpuCC:glycine betaine complex (Du et al., 2011) (Fig. 6) as the starting structure for our in silico modeling study. Within the OpuCC protein, the positively charged trimethlyammonium head group of glycine betaine is housed and coordinated via four Tyr residues $\left(\mathrm{Tyr}^{71}, \mathrm{Tyr}^{117}, \mathrm{Tyr}^{197}\right.$ and $\left.\mathrm{Tyr}^{221}\right)$ arranged in form of an aromatic cage. The carboxylate of glycine betaine protrudes out of this aromatic cage and is bound and spatially orientated within the binding site via interactions with $\mathrm{Gln}^{19}$ and $\mathrm{Thr}^{74}$ (Du et al., 2011). Our in silico docking experiment suggests a similar, but not identical, position of the DMSP molecule within the ligand-binding site (Fig. 6). Despite the shift in the overall position of the DMSP molecule, the same stabilizing interactions found for the glycine betaine ligand in the experimentally determined OpuCC:glycine betaine complex are also present in the in silico generated OpuCC:DMSP structure (Fig. 6). As expected, the positively charged dimethylsulfonio head group of DMSP is accommodated within the aromatic cage via cation$\pi$ interactions. The carboxylate of DMSP, however, interacts differently with the OpuCC protein, a result of the increased chain length of the DMSP molecule. While the interaction of the DMSP ligand with $\mathrm{Gln}^{19}$ is retained, the interaction with $\mathrm{Thr}^{74}$ is lost and instead a new interaction with the backbone nitrogen of $\mathrm{Ser}^{51}$ is established (Fig. 6). Notably, such an interaction of the carboxylate of the carnitine ligand with the backbone of $\mathrm{Ser}^{51}$ has also been observed in the crystal structure of the OpuCC:carnitine complex (Du et al., 2011). Hence, the described spatial orientation for ligands with 
297 an increased length in their main carbon chain (e.g., carnitine and DMSP) seems to represent a stable

298 interaction platform with the OpuCC solute receptor protein. This will subsequently allow high-

299 affinity import of these types of substrates via the OpuC transporter as found here for DMSP (Table 2)

300 and as already reported for carnitine (Kappes and Bremer, 1998).

301

302

Bioinformatics assessment of the distribution of OpuA- and OpuC-type transporters within the genus

\section{Bacillus}

304 Since our growth assays and transport studies revealed the reliance of DMSP import on the OpuA and

305 OpuC transporters, we wondered how widely these compatible solute uptake systems are distributed

306 among members of the genus Bacillus. We therefore conducted a BLAST-P analysis of Bacillus

307 species with fully sequenced genomes represented in the Integrated Microbial Genomes and

308 Metagenomes database maintained by the DOE Joint Genome Institute (Nordberg et al., 2013). We

309 used for this search the amino acid sequences of the OpuAC and OpuCC solute receptor proteins

310 (Kempf and Bremer, 1995; Kappes et al., 1999) as the query sequences. This search uncovered 88

311 finished genome sequences that are derived from 18 distinct Bacillus species; 84 strains possessed an

312 OpuAC protein and 86 strains possessed OpuCC (Table S1). Hence, OpuA- and OpuC-type

313 transporters are found in essentially every Bacillus species whose genome sequence was inspected.

314 The vast majority (82 out of 88 ) simultaneously possesses both OpuA and OpuC; none of the

315 inspected genomes lacked both of these osmolyte uptake systems (Table S1). An alignment of the

316 amino acid sequences of the retrieved OpuAC and OpuCC proteins revealed that the amino acids

317 forming the characteristic aromatic ligand binding cages (Horn et al., 2006; Smits et al., 2008; Du et

318 al., 2011) are highly conserved and would therefore be able to contribute to DMSP binding via cation-

$319 \pi$ interactions as suggested by our in silico modeling studies (Fig. 6).

320

321 Discussion

322 Members of the genus Bacillus are ubiquitous in nature (Earl et al., 2008; Logan and De Vos, 2009)

323 and can be found in marine and estuarine ecosystems and in sediments (Siefert et al., 2000; Miranda et

324 al., 2008; Ettoumi et al., 2013). It is highly likely that B. subtilis will have access to DMSP in these 
325 habitats since this compound is produced abundantly in marine environments (Stefels, 2000; Yoch,

326 2002; Curson et al., 2011a; Reisch et al., 2011; Moran et al., 2012). In contrast to many 327 microorganisms living in marine ecosystems (Curson et al., 2011b; Rinta-Kanto et al., 2011; Levine et 328 al., 2012; Rinta-Kanto et al., 2012; Todd et al., 2012), our data show that B. subtilis cannot use DMSP 329 as a nutrient. However, it can exploit DMSP as an excellent stress protectant against challenges 330 conferred by sustained high salinity or lasting extremes in high and low growth temperature. This can 331 be done with a degree of efficiency matching that of the stress-protective effects of glycine betaine, 332 probably the most widely used compatible solute in nature (Yancey, 2005).

333 By chemical profiling a set of well-defined transporter mutants, we found that DMSP uptake

334 by osmotically and temperature-stressed $B$. subtilis cells are mediated under laboratory conditions by 335 two ABC transport systems, OpuA and OpuC. The in silico assessment of the occurrence of these 336 transporters revealed their presence in most Bacilli with a fully sequenced genome. We therefore 337 surmise that the osmotic and temperature stress protection afforded through DMSP import that we 338 describe here in detail for the model organism B. subtilis (Barbe et al., 2009; Belda et al., 2013) will 339 be of ecophysiological relevance for most members of the large and diverse Bacillus genus (Earl et al., 340 2008; Logan and De Vos, 2009).

341 The very low affinity of OpuA for DMSP $\left(K_{i}\right.$ of about $\left.1 \mathrm{mM}\right)$ suggests a limited importance of

342 this transport system for DMSP uptake in natural settings where this compound is typically found in 343 rather low concentrations (Kiene et al., 1998; Van Duyl et al., 1998; Vila-Costa et al., 2006). OpuC, 344 on the other hand, is a high-affinity uptake system and cannot only scavenge DMSP $\left(K_{i}\right.$ of about 40 $345 \mu \mathrm{M}$ ), but also its natural selenium analogue DMSeP and several synthetic DMSP derivatives with 346 similar high affinities. To the best of our knowledge, the transport data that we provide here for DMSP 347 uptake in B. subtilis via the OpuA and OpuC systems are the first truly quantitative measurements 348 reported for any defined microbial species. Our data also identify the first uptake system (OpuC) for 349 the naturally occurring derivative of DMSP, DMSeP (Ansede and Yoch, 1997; Ansede et al., 1999), in 350 any microorganism and pinpoint $\mathrm{OpuC}$ as a flexible transporter through which various synthetic 351 DMSP derivatives (Dickschat et al., 2010; Brock et al., 2014) can be efficiently taken up. 
The $\mathrm{ABC}$ transporter $\mathrm{OpuC}$ is a remarkable osmolyte import system since its substrate

353

354

355

356

357

358

359

360

361

362

363

364

365

366

367

368

369

370

371

372

373

374

375

376

377

378

379

specificity is extremely broad (Bremer, 2002; Hoffmann and Bremer, 2011; Bashir et al., 2014b).

Most of its ligands possess positively charged and fully methylated head-groups, and these are accommodated via cation- $\pi$ interactions within an aromatic cage formed by four tyrosine residues present in the extracellular OpuCC substrate-binding protein (Kappes et al., 1999; Du et al., 2011).

Given what is known about the molecular determinants for compatible solute binding by substratebinding proteins of $\mathrm{ABC}$ transporters (Bremer, 2011; Tschapek et al., 2011), it is not surprising that OpuCC can accommodate DMSP and its selenium and tellurium analogues within its ligand-binding site with good affinities, as evidenced by the low $K_{i}$ values of the OpuC transporter for these compounds,

The ligand-binding site present in OpuCC exhibits a considerable degree of structural flexibility (Du et al., 2011) and allows, as suggested by our modeling studies, the capture of ligands with different chain length (e.g., glycine betaine, carnitine and DMSP) through a switch in the binding mode of the carboxylate of its substrates. What is rather surprising, however, is our finding that the sulfur head-group of DMSP can be extensively chemically modified with no significant reduction in the affinity of the OpuC transporter for these synthetic ligands. This is reminiscent of the OpuCmediated import by B. subtilis of a toxic synthetic glycine betaine derivative [2-(dimethyl(4nitrobenzyl)ammonio) acetate] in which a bulky benzyl group substituted one of its methyl groups (Cosquer et al., 2004). Collectively, the structural plasticity of the OpuCC ligand-binding site (Du et al., 2011) provides the molecular underpinning for the promiscuous nature of the OpuC $\mathrm{ABC}$ transport system (Hoffmann et al., 2013; Bashir et al., 2014b).

DMSP import competes with the uptake of glycine betaine in natural marine settings (Kiene et al., 1998; Vila-Costa et al., 2006) and microbial transport systems that mediate glycine betaine uptake are frequently also used for DMSP import (Gouesbet et al., 1994; Pichereau et al., 1998; Cosquer et al., 1999; Murdock et al., 2014). B. subtilis is no exception in this regard since both OpuA and OpuC serve for high-affinity glycine betaine import as well (Kempf and Bremer, 1995; Kappes et al., 1996; Kappes et al., 1999). We note in this context, however, that not all microbial glycine betaine import systems can mediate DMSP uptake. This is exemplified by the substrate profile of the B. subtilis 
380 OpuD transporter, a system that catalyzes glycine betaine import (Kappes et al., 1996) but does not 381 participate in DMSP uptake. OpuD is a member of the BCCT (betaine-carnitine-choline-transporter) 382 family, carriers that are involved in the uptake of various types of compatible solutes (Ziegler et al., 383 2010). Interestingly, a member (DddT) of the BCCT family was recently identified as a DMSP uptake 384 system in several DMSP-catabolizing species but it was also proficient in glycine betaine import when 385 assessed in a heterologous E. coli system (Todd et al., 2010; Sun et al., 2012).

386 The growth-enhancing effects of compatible solutes for osmotically stressed bacterial cells 387 probably stem from a combination of their beneficial influence on cellular hydration and turgor, on the 388 ionic strength and solvent properties of the cytoplasm, on the preservation of the solubility of proteins 389 and their functionality, and the maintenance of the integrity of cell components and biosynthetic 390 processes (Cayley et al., 1992; Bourot et al., 2000; Bremer and Krämer, 2000; Diamant et al., 2001; 391 Ignatova and Gierasch, 2006; Street et al., 2010; Auton et al., 2011; Wood, 2011). The physico392 chemical attributes of individual compatible solutes (Street et al., 2006; Auton et al., 2011; Diehl et 393 al., 2013; Jackson-Atogi et al., 2013) are, however, also an important determinant for the efficiency 394 and type by which they exert their protective function. For instance, the oxidation of ectoine to 5395 hydroxyectoine (Bursy et al., 2007) results in a far better desiccation protection for molecules than that 396 afforded by its precursor ectoine (Tanne et al., 2014), which itself is an excellent stress protectant 397 against various types of challenges (Lippert and Galinski, 1992; Widderich et al., 2014). Similarly, the 398 disparate effects of glycine betaine and proline on the cellular content of potassium, glutamate, and 399 trehalose, and hence on the water activity and osmotic pressure of the cytoplasm, are large enough to 400 make glycine betaine a far more effective osmoprotectant for E. coli than proline (Cayley et al., 1992).

401 We probably see all these effects at work when one collectively views the different influence of 402 DMSP and its natural and synthetic derivatives on the growth of salt-challenged $B$. subtilis cells, on 403 the build-up of the osmostress-adaptive proline pool, and on gene expression of the osmotically 404 controlled opuA operon.

405 Cellular protection by compatible solute accumulation against sustained low and high growth 406 temperatures has been reported for a considerable number of microbial species [for a detailed set of 407 references see: (Holtmann and Bremer, 2004; Hoffmann and Bremer, 2011)]. However, the underlying 
408

409

410

411

412

413

414

415

416

417

418

419

422

423

424

425

427

428

429

430

431

432

433

434

435

molecular mechanisms are insufficiently understood. Studies in B. subtilis with the cold- and heatstress protectant glycine betaine have shown that the cellular pools of this compound attained under temperature stress are far lower than those established under osmotic stress conditions (Holtmann and Bremer, 2004; Hoffmann and Bremer, 2011; Hoffmann et al., 2013). This observation indicates that the mechanism(s) for protection by glycine betaine against osmotic and temperature challenges are, at least partially, different. Since cold stress can have significant effects on protein structure (Jaenicke, 1990), the cryoprotective effects of DMSP for B. subtilis and other microorganisms (Bayles and Wilkinson, 2000; Angelidis and Smith, 2003; Murdock et al., 2014) might primarily stem from its function as a chemical chaperone. Indeed, DMSP is known to stabilize in vitro the enzyme activities of purified phosphofructokinase from rabbit muscle, the cold-labile model enzyme lacate dehydrogenase, and of the malate dehydrogenase from the polar alga Acrosiphonia arcta under coldinduced denaturing conditions (Nishiguchi and Somero, 1992; Karsten et al., 1996).

Our work with B. subtilis also revealed a new facet of the physiological attributes of DMSP since it conferred effective heat stress protection. As argued above for cold stress protection, the heatstress protective effects of DMSP might also be ascribed to the chemical chaperone activity of compatible solutes (Caldas et al., 1999; Diamant et al., 2001; Chattopadhyay et al., 2004; Tschapek et al., 2011).

In summary, DMSP not only proved to be a formidable protectant against osmotic stress, but it also effectively rescued growth at the very upper and lower edges of the temperature spectrum that $B$. subtilis cells can populate. Under these conditions, other prominent cellular defense systems of $B$. subtilis (e.g. the cold- and heat-shock response and the SigB-controlled general stress response) fail but DMSP does the job.

\section{Experimental procedures}

Chemicals and synthesis of synthetic DMSP derivatives

Glycine betaine, carnitine, the chromogenic substrate [para-nitrophenyl- $\alpha$-D-glucopyranoside; (PNPG)] used for assays of the TreA reporter enzyme, a salt-tolerant phospho- $\alpha-(1,1)$-glucosidase (Gotsche and Dahl, 1995), and the ninhydrin reagent used for the quantification of proline by a 
436 colorimetric assay (Bates et al., 1973) were purchased from Sigma-Aldrich (Steinheim, Germany).

437 Radiolabeled $\left[1-{ }^{14} \mathrm{C}\right] \mathrm{glycine}$ betaine $\left(55 \mathrm{mCi} \mathrm{mmol}^{-1}\right)$ was obtained from American Radiolabeled 438 Chemicals Inc. (St. Louis, MO; USA). Dimethylsulfoniopropionate (DMSP) was purchased from 439 Carbon Scientific Co. LTD (London, United Kingdom). The antibiotics kanamycin, erythromycin, 440 spectinomycin, and tetracycline were obtained from SERVA Electrophoreses GmbH (Heidelberg, 441 Germany), United States Biochemical Corp. (Cleveland, Ohio; USA) and Sigma-Aldrich (Steinheim; 442 Germany), respectively. Chemicals for the synthesis of DMSP and its derivatives were obtained from 443 Sigma-Aldrich (Steinheim; Germany), or Acros Organics (Thermo Fisher Scientific, Geel; Belgium) 444 and used without further purification. The synthesis of DMSP, dimethylseleniopropionate (DMSeP), 445 dimethyltelluriopropionate $\quad$ (DMTeP), ethylmethylsulfoniopropionate $\quad$ (EMSP), 446 diethylsulfoniopropionate (DESP), methylpropylsulfoniopropionate $\quad$ (MPSP), 447 isopropylmethylsulfoniopropionate (IMSP), and tetramethylenesulfoniopropionate (TMSP) was 448 performed by acid-catalyzed Michael addition of the corresponding dialkyl chalcogenides to acrylic 449 acid as detailed previously (Dickschat et al., 2010; Brock et al., 2014).

450

\section{Media and growth conditions for B. subtilis strains}

452 B. subtilis strains were routinely maintained on Luria-Bertani (LB) agar plates or cultured in LB liquid 453 medium (Miller, 1972). The antibiotic concentrations for the seletion of B. subtilis strains carrying 454 chromosomal mutant alleles marked with an antibiotic resistance cassette were as follows: kanamycin $455\left(5 \mu \mathrm{g} \mathrm{ml}^{-1}\right)$, erythromycin $\left(1 \mu \mathrm{g} \mathrm{ml}^{-1}\right)$, spectinomycin $\left(100 \mu \mathrm{g} \mathrm{ml}^{-1}\right)$, and tetracycline $\left(10 \mu \mathrm{g} \mathrm{ml} \mathrm{l}^{-1}\right)$. For stress protection growth assays by compatible solutes, B. subtilis strains were cultivated in Spizizen's 457 minimal medium (SMM) with $0.5 \%(\mathrm{wt} / \mathrm{vol})$ glucose as the carbon source and a solution of trace 458 elements (Harwood and Archibald, 1990). L-tryptophan and L-phenylalanine were added to growth 459 media at final concentrations of $40 \mathrm{mg} \mathrm{ml}^{-1}$ and $36 \mathrm{mg} \mathrm{ml}^{-1}$, respectively, to satisfy the growth 460 requirements of the $B$. subtilis strains JH642 and 168 and their mutant derivatives (Table 3). When the 461 use of DMSP by $B$. subtilis as either sole carbon source was tested, the glucose content (28 $\mathrm{mM})$ in

462 SMM was replaced by $33 \mathrm{mM}$ DMSP; likewise, when the use of DMSP as sole sulfur source was 463 assessed, the sulfur source present in $\mathrm{SMM}\left[\left(\mathrm{NH}_{4}\right)_{2} \mathrm{SO}_{4} ; 15 \mathrm{mM}\right]$ was replaced by $15 \mathrm{mM}$ DMSP in 
464 the presence of $\left[\left(\mathrm{NH}_{4}\right)_{2} \mathrm{PO}_{4} ; 15 \mathrm{mM}\right]$ and $\mathrm{MgSO}_{4}$ was replaced by $\mathrm{MgCl}_{2}$. Use of DMSP as a nutrient

465 was also tested at a substrate concentration of $2 \mathrm{mM}$ to assess possible toxic effects of higher DMSP 466 concentrations on growth. The osmolarity of the SMM was increased by the addition of $\mathrm{NaCl}$ from a 5 467 M stock solution. Compatible solutes were sterilized by filtration (Filtropur S $0.2 \mu$ m; Sarstedt, 468 Nürnbrecht, Germany) and were added to growth media at a finally concentration of $1 \mathrm{mM}$. Cultures 469 of $B$. subtilis cells were inoculated from exponentially growing pre-cultures in pre-warmed SMM to 470 optical densities $\left(\mathrm{OD}_{578 \mathrm{~nm}}\right)$ of 0.1 . B. subtilis cultures were grown in 20-ml culture volumes in $100-\mathrm{ml}$ 471 Erlenmeyer flasks set in a shaking (set to 220 r.p.m.) water bath. Cultures used for heat-stress growth 472 protection assays at $52^{\circ} \mathrm{C}$ were inoculated from pre-cultures grown at $37^{\circ} \mathrm{C}$ to an $\mathrm{OD}_{578}$ of about 1 to 473 an $\mathrm{OD}_{578}$ of 0.1 . The cultures were set in a water bath with a temperature of $37^{\circ} \mathrm{C}$; the growth 474 temperature was then slowly increased to $52^{\circ} \mathrm{C}$ over a $20 \mathrm{~min}$ time frame. The temperature of the 475 water baths used for the heat and cold stress growth experiments was set and controlled with the aid of 476 a calibrated thermometer (Testo AG, Lenzkirch, Germany).

Bacterial strains

479 The B. subtilis strains JH642 (trpC2 pheA1) (Brehm et al., 1973) (Table 3), a member of the 480 domesticated inage of laboratory strains (Smith et al., 2014), was used for all experiments that 481 addressed the salt- and heat-stress protective potential of DMSP and its derivatives. Since it carries a 482 mutation in the $i l v B$ gene that makes it cold sensitive (Wiegeshoff and Marahiel, 2007), the $B$. subtilis 483 laboratory strain 168 (Barbe et al., 2009) (Table 3) was used for studies that probed the potential of 484 these solutes as cold stress protectants. To analyze the transporter activities of individual Opu uptake 485 systems and to avoid a possible cross-talk of components of a given Opu ABC-transporter with 486 another Opu systems, we constructed a set of strains that carry deletions of the complete operons 487 coding for the OpuA-, OpuB- and OpuC ABC transporters. Strain TMB107 [ $($ opuA::tet $) 3$ ] was 488 constructed by replacing a 2700 bp 'ориAA-ориAB-ориAC' DNA fragment with a 1834 bp DNA 489 fragment carrying a tetracycline resistance cassette which was derived from plasmid pDG1515 490 (Guerout-Fleury et al., 1995). Strain TMB116 [ $\Delta($ opuB::ery)1] carries a 3139 bp 'opuBA-opuBB491 оривС-ориBD' deletion that was replaced with a erythromycin resistance cassette (1 $553 \mathrm{bp}$ ) derived 
492 from plasmid pDG647 (Guerout-Fleury et al., 1995). The [ $\Delta($ opuC::spc)3] mutation was constructed 493 by replacing a 3419 bp 'ориСА-ориСВ-ориСС-ориCD'-fragment with a 1173 bp DNA fragment 494 encoding a spectinomycin resistance cassette which was derived from plasmid pDG1726 (Guerout495 Fleury et al., 1995). The formerly described strain RMKB7 carries a gene disruption in the 496 opuD gene that encodes a single component glycine betaine uptake system (Kappes et al., 497 1996). Combinations of single opu mutations were constructed by transforming appropriate 498 recipient strains with chromosomal DNA of B. subtilis mutants carrying various opu alleles marked 499 with antibiotic resistance cassettes (Table 3). Preparation of chromosomal DNA from B. subtilis 500 strains, transformation of B. subtilis with this DNA, and the selection of transformants via their 501 antibiotic resistance were conducted according to routine procedures (Cutting and Vander Horn, 1990;

502 Harwood and Archibald, 1990). Derivatives of the B. subtilis strain 168 carrying gene disruption 503 mutations have been described before (Hoffmann and Bremer, 2011).

504

Determination of cellular proline pools in osmotically stressed cells

506 The intracellular proline content of osmotically stressed cells of the wild-type JH642 strain was 507 determined by a colorimetric assay detecting proline as a colored prolin-ninhydrine complex, which 508 can be quantified by measuring the absorption of the solution at $480 \mathrm{~nm}$ in a spectrophotometer (Bates 509 et al., 1973). Cells of strain JH642 were grown in SMM containing 1. 2M NaCl in the absence or 510 presence of various concentrations $(25 \mu \mathrm{M}$ to $1000 \mu \mathrm{M})$ of glycine betaine, DMSP, DMSeP, DMTeP, 511 EMSP, DESP, IMSP and TMSP until they reached an $\mathrm{OD}_{578 \mathrm{~nm}}$ of about 1.6. Harvesting of the cells by 512 centrifugation, their processing for the colorimetric proline detection assay, and the details of the 513 calculation of the intracellular volume of B. subtilis and of the concentration of proline have all been 514 described previously (Hoffmann and Bremer, 2011; Hoffmann et al., 2013).

515

516 Transport studies

517 Cultures of the B. subtilis strains SBB1 $\left(\mathrm{OpuA}^{+}\right)$and SBB2 $\left(\mathrm{OpuC}^{+}\right)($Table 3) were grown in SMM 518 containing $0.4 \mathrm{M} \mathrm{NaCl}$ to an $\mathrm{OD}_{578 \mathrm{~nm}}$ of about 0.3 . 2-ml aliquots were withdrawn and mixed with a 519 solution of glycine betaine that that been spiked with $\left[1-{ }^{14} \mathrm{C}\right]$ glycine betaine; the final glycine betaine 
520

521

522

523

524

525

526

527

528

529

530

531

532

533

534

535

536

537

538

539

540

541

542

543

544

545

546

concentration in the uptake assays was varied between $3 \mu \mathrm{M}$ and $100 \mu \mathrm{M}$. The transport assays were conducted in the presence of non-radiolabeled DMSP for the OpuA ${ }^{+}$strain SBB1 and non-radiolabeled DMSP, DMSeP, DMTeP, EMSP, DESP, IMSP, and TMSP for the OpuC ${ }^{+}$strain SBB2. In the transport studies conducted with strain SBB1, DMSP was present as an inhibitor for glycine betaine uptake at a final substrate concentration of $1000 \mu \mathrm{M}$. For glycine betaine uptake assays conducted with strain SBB2, the substrate concentration for the inhibitors was set to a final concentration of 150 $\mu \mathrm{M}$. Uptake assays, processing of the cells, and the quantification of the imported radiolabeled glycine betaine by scintillation counting followed previously established procedures (Kappes et al., 1996). Michaelis-Menten kinetics of $\left[1-{ }^{14} \mathrm{C}\right] \mathrm{glycine}$ betaine uptake and fitting of the competitive inhibition of this transport activity by DMSP and its derivatives were performed with the GraphPad Prism 5 software (GraphPad Software, Inc., La Jolla, CA, USA).

\section{Measurements of TreA enzyme activity in opuA-treA reporter fusion strains}

The B. subtilis strain MBB9 carries a opuA-treA operon fusion that is expressed from the opuA promoter; it is stably inserted via a double-recombination event in the non-essential amyE gene (Hoffmann et al., 2013) (Table 3). The expression level of this reporter gene fusion is responsive to both osmotic stress and the intracellular pools of different compatible solutes (Hoffmann et al., 2013; Bashir et al., 2014b; Bashir et al., 2014a). Cells of strain MBB9 were grown in SMM or in SMM containing $1.2 \mathrm{M} \mathrm{NaCl}$ in either the absence or the presence of glycine betaine, DMSP, DMSeP, DMTeP, EMSP, DESP, IMSP, and TMSP (the final substrate concentrations of these compounds in the medium was were $1 \mathrm{mM}$ ) to mid-exponential growth phase (OD ${ }_{578 \mathrm{~nm}}$ of about 1.5 ), harvested by centrifugation, and then processed for TreA enzyme activity assays as described previously (Gotsche and Dahl, 1995; Hoffmann et al., 2013). One unit (U) of TreA activity is defined as the enzymatic conversion of $1 \mu \mathrm{mol}$ of the colorimetric substrate PNPG per min. Protein concentrations of the samples were estimated from the optical density of the B. subtilis cell culture (Miller, 1972).

in silico docking of DMSP into the ligand-binding sites of the OpuAC and OpuCC proteins 
547 The presumed molecular interaction of DMSP with the OpuAC and OpuCC proteins were assessed by 548 in silico docking. The OpuAC:DMSA crystal structure (Smits et al., 2008) was used as the template 549 for the OpuAC:DMSP in silico model. The DMSA ligand in the OpuAC:DMSA complex was first 550 exchanged with a DMSP molecule and the generated OpuAC:DMSP model was then refined against 551 the structure factors of the OpuAC:DMSA dataset (Protein database entry 3CHG) (Smits et al., 2008) 552 using the programs COOT and REFMAC (Murshudov et al., 1997; Emsley and Cowtan, 2004) to 553 define the bond lengths and angle of the in silico DMSP ligand docked into the OpuAC binding site. 554 The coordinate file for the DMSP ligand was extracted from the crystal structure of the DMSP lyase 555 DddQ (PDB database entry 4LA2) (Li et al., 2014). After refining the in silico-generated model, the 556 orientation of DMSP within the ligand-binding site was manually checked by analyzing the 557 interactions of the DMSP molecule with the OpuAC protein within a distance range of 2.8-3.2 $\AA$ from 558 the ligand. A similar procedure was used for generating an in silico model of the OpuCC:DMSP 559 complex, except that the OpuCC:glycine betaine crystal structure (PDB code 3PPP) (Du et al., 2011) 560 was used as the template. First, the in silico-generated OpuAC:DMSP complex was overlaid with the 561 OpuCC:glycine betaine crystal structure. Then, the location of the glycine betaine and DMSP ligands 562 was superimposed and after removing the glycine betaine ligand from the OpuCC:glycine betaine 563 crystal structure, the DMSP coordinates were transferred in silico into the OpuCC protein. The thereby 564 generated OpuCC:DMSP complex was than refined and analyzed as described above for the 565 OpuAC:DMSP in silico complex.

566

Preparation of figures of crystal structures of the in silico derived OpuAC:DMSP and OpuCC:DMSP complexes

569 Figures of the crystal structures of the OpuAC protein in complex with dimethylsulfonioacetate 570 (DMSA) (PDB code 3CHG) (Smits et al., 2008), of the OpuCC protein in complex with glycine 571 betaine (PDB code 3PPP) (Du et al., 2011), and of the in silico generated OpuAC:DMSP and 572 OpuCC:DMSP complexes generated in this study were prepared using the PyMOL software package 573 (http://www.pymol.org). 
575

576

577

578

579

580

581

582

583

584

585

586

587

588

589

590

591

592

593

594

595

596

597

598

599

600

601

602

603

Database searches and phylogenetic analysis of the distribution of OpuA- and OpuC-type transporters in Bacilli

The amino acid sequence of the ligand-binding proteins (OpuAC, OpuCC) of the OpuA and OpuC ABC transporters (Kempf and Bremer, 1995; Kappes et al., 1999) were retrieved from the nucleotide sequence of the B. subtilis laboratory strain 168 (Barbe et al., 2009) and used as query sequences for BLAST-P database searches at the Integrated Microbial Genomes and Metagenomes database (IMG; https://img.jgi.doe.gov/cgi-bin/w/main.cgi) maintained by the the Department of Energy (DOE) Joint Genome Institute (Nordberg et al., 2013). We focused our analysis on members of the Bacillus genus with a finished genome sequence. The retrieved OpuAC and OpuCC amino acid sequences were aligned using Clustal W (Thompson et al., 2000) for inspection of conserved residues, in particular for those that from the aromatic cages in the OpuAC and OpuCC proteins (Horn et al., 2006; Du et al., 2011). The genome context of the opиAC and ориCC genes for the remaining components of the OpuA and OpuC ABC transporters (Kempf and Bremer, 1995; Kappes et al., 1999) was assessed with the bioinformatics tool provided by the IMG platform.

\section{Acknowledgments}

We thank Johann Heider (University of Marburg) for his helpful discussions on the chemical properties of DMSP, DMSeP, and DMTeP and Lutz Schmitt (University of Düsseldorf) for his continued interest in this project. We gratefully acknowledge the kind help of Vickie Koogle in the language editing of our manuscript. Funding for this study was provided through the LOEWE program of the State of Hessen (via the Centre for Synthetic Microbiology; Synmicro, Marburg) and by a contribution by the Fonds der Chemischen Industrie (both to E.B). Work in the laboratory of J.D.S. was funded by the Deutsche Forschungsgemeinschaft (DFG) in the framework of the Transregional Collaborative Research Centre SFB TRR 51 (“Roseobacter") at the University of Braunschweig. N.L.B. was supported by a scholarship from the Fonds der Chemischen Industrie. The Institute for Biochemistry (University of Düsseldorf) supported the work of S.H.J.S. 
604

605

606

607

608

609

610

611

612

613

614

615

616

617

618

619

620

621

622

623

624

625

626

627

628

629

630

631

632

633

634

635

636

637

638

639

640

\section{References}

Akashi, H., and Gojobori, T. (2002) Metabolic efficiency and amino acid composition in the proteomes of Escherichia coli and Bacillus subtilis. Proc Natl Acad Sci U S A 99: 3695-3700.

Angelidis, A.S., and Smith, G.M. (2003) Role of the glycine betaine and carnitine transporters in adaptation of Listeria monocytogenes to chill stress in defined medium. Appl Environ Microbiol 69: $7492-7498$.

Ansede, J.H., and Yoch, D.C. (1997) Comparison of selenium and sulfur volatilization by dimethlysulfoniopropionate lyase (DMSP) in two marine bacteria and estuarine sediments. FEMS Microbiol Ecol 23: 315-324.

Ansede, J.H., Pellechia, P.J., and Yoch, D.C. (1999) Selenium biotransformation by the salt marsch corsgrass Spartina alterniflora: evidence for dimethlylselenoniopropionate formation. Environ Sci Technol 33: 2064-2069.

Auton, M., Rösgen, J., Sinev, M., Holthauzen, L.M., and Bolen, D.W. (2011) Osmolyte effects on protein stability and solubility: a balancing act between backbone and side-chains. Biophys Chem 159: 90-99.

Barbe, V., Cruveiller, S., Kunst, F., Lenoble, P., Meurice, G., Sekowska, A. et al. (2009) From a consortium sequence to a unified sequence: the Bacillus subtilis 168 reference genome a decade later. Microbiology 155: 1758-1775.

Bashir, A., Hoffmann, T., Smits, S.H., and Bremer, E. (2014a) Dimethlyglycine provides salt and temperature stress protection to Bacillus subtilis. Appl Environ Microbiol 80: 2773-2785.

Bashir, A., Hoffmann, T., Kempf, B., Xie, X., Smits, S.H., and Bremer, E. (2014b) The plant-derived compatible solutes proline betaine and betonicine confer enhanced osmotic and temperature stress tolerance to Bacillus subtilis. Microbiology 160: 2283-2294.

Bates, S.L., Waldren, R.P., and Teare, I.D. (1973) Rapid determination of free proline for water-stress studies. Plant and Soil 39: 205-207.

Bayles, D.O., and Wilkinson, B.J. (2000) Osmoprotectants and cryoprotectants for Listeria monocytogenes. Lett Appl Microbiol 30: 23-27.

Belda, E., Sekowska, A., Le Fevre, F., Morgat, A., Mornico, D., Ouzounis, C. et al. (2013) An updated metabolic view of the Bacillus subtilis 168 genome. Microbiology 159: 757-770.

Berntsson, R.P., Smits, S.H., Schmitt, L., Slotboom, D.J., and Poolman, B. (2010) A structural classification of substrate-binding proteins. FEBS letters 584: 2606-2617.

Boch, J., Kempf, B., and Bremer, E. (1994) Osmoregulation in Bacillus subtilis: synthesis of the osmoprotectant glycine betaine from exogenously provided choline. J Bacteriol 176: 5364-5371.

637 Bourot, S., Sire, O., Trautwetter, A., Touze, T., Wu, L.F., Blanco, C., and Bernard, T. (2000) Glycine 38 betaine-assisted protein folding in a lysA mutant of Escherichia coli. J Biol Chem 275: 1050-1056.

639 Brehm, S.P., Staal, S.P., and Hoch, J.A. (1973) Phenotypes of pleiotropic-negative sporulation mutants of Bacillus subtilis. J Bacteriol 115: 1063-1070. 
641 Bremer, E. (2002) Adaptation to changing osmolarity. In Bacillus subtilis and its closes relatives:

642 from genes to cells. Sonenshein, A.L., Hoch, J.A., and Losick, R. (eds). Washington, D.C.: ASM 643 Press, pp. 385-391.

644 Bremer, E. (2011) Crystal ball - 2011. A look into the aromatic cage. Environmental Microbiology 645 Rep 3: 1-5.

646 Bremer, E., and Krämer, R. (2000) Coping with osmotic challenges: osmoregulation through 647 accumulation and release of compatible solutes. In Bacterial Stress Responses. Storz, G., and Hengge648 Aronis, R. (eds): ASM Press, pp. 79-97.

649 Brill, J., Hoffmann, T., Bleisteiner, M., and Bremer, E. (2011) Osmotically controlled synthesis of the 650 compatible solute proline is critical for cellular defense of Bacillus subtilis against high osmolarity. $J$ 651 Bacteriol 193: 5335-5346.

652 Brock, N.L., Menke, M., Klapschinski, T.A., and Dickschat, J.S. (2014) Marine bacteria from the 653 Roseobacter clade produce sulfur volatiles via amino acid and dimethylsulfoniopropionate catabolism.

654 Org Biomol Chem 12: 4318-4323.

655 Bursy, J., Pierik, A.J., Pica, N., and Bremer, E. (2007) Osmotically induced synthesis of the 656 compatible solute hydroxyectoine is mediated by an evolutionarily conserved ectoine hydroxylase. $J$ 657 Biol Chem 282: 31147-31155.

658 Caldas, T., Demont-Caulet, N., Ghazi, A., and Richarme, G. (1999) Thermoprotection by glycine 659 betaine and choline. Microbiology 145 2543-2548.

660 Cayley, S., Lewis, B.A., and Record, M.T., Jr. (1992) Origins of the osmoprotective properties of 661 betaine and proline in Escherichia coli K-12. J Bacteriol 174: 1586-1595.

662 Charlson, R.J., Lovelock, J.E., Andreae, M.O., and Warren, S.G. (1987) Oceanic phytoplancton, 663 atmospheric sulphur, cloud albedo and climate. Nature 326: 655-661.

664 Chattopadhyay, M.K., Kern, R., Mistou, M.Y., Dandekar, A.M., Uratsu, S.L., and Richarme, G.

665 (2004) The chemical chaperone proline relieves the thermosensitivity of a dnaK deletion mutant at 42 666 degrees C. J Bacteriol 186: 8149-8152.

667 Cosquer, A., Pichereau, V., Pocard, J.A., Minet, J., Cormier, M., and Bernard, T. (1999) Nanomolar 668 levels of dimethylsulfoniopropionate, dimethylsulfonioacetate, and glycine betaine are sufficient to 669 confer osmoprotection to Escherichia coli. Appl Environ Microbiol 65: 3304-3311.

670 Cosquer, A., Ficamos, M., Jebbar, M., Corbel, J.C., Choquet, G., Fontenelle, C. et al. (2004) 671 Antibacterial activity of glycine betaine analogues: involvement of osmoporters. Bioorg Med Chem 672 Lett 14: 2061-2065.

673 Curson, A.R., Todd, J.D., Sullivan, M.J., and Johnston, A.W. (2011a) Catabolism of 674 dimethylsulphoniopropionate: microorganisms, enzymes and genes. Nat Rev Microbiol 9: 849-859.

675 Curson, A.R., Sullivan, M.J., Todd, J.D., and Johnston, A.W. (2011b) DddY, a periplasmic 676 dimethylsulfoniopropionate lyase found in taxonomically diverse species of Proteobacteria. ISME J 5: $677 \quad 1191-1200$. 
678 Cutting, S.M., and Vander Horn, P.B. (1990) Genetic analysis. In Molecular biological methods for

679 Bacillus. Harwood, C.R., and Cutting, S.M. (eds). Chichester, UK: John Wiley \& Sons, Inc., pp. 2768074.

681 Diamant, S., Eliahu, N., Rosenthal, D., and Goloubinoff, P. (2001) Chemical chaperones regulate 682 molecular chaperones in vitro and in cells under combined salt and heat stresses. J Biol Chem 276: 683 39586-39591.

684 Dickschat, J.S., Zell, C., and Brock, N.L. (2010) Pathways and substrate specificity of DMSP 685 catabolism in marine bacteria of the Roseobacter clade. Chembiochem 11: 417-425.

686 Diehl, R.C., Guinn, E.J., Capp, M.W., Tsodikov, O.V., and Record, M.T., Jr. (2013) Quantifying 687 additive interactions of the osmolyte proline with individual functional groups of proteins: 688 comparisons with urea and glycine betaine, interpretation of m-values. Biochemistry 52: 5997-6010.

689 Du, Y., Shi, W.W., He, Y.X., Yang, Y.H., Zhou, C.Z., and Chen, Y. (2011) Structures of the 690 substrate-binding protein provide insights into the multiple compatible solute binding specificities of 691 the Bacillus subtilis ABC transporter OpuC. Biochem J 436: 283-289.

692 Earl, A.M., Losick, R., and Kolter, R. (2008) Ecology and genomics of Bacillus subtilis. Trends 693 Microbiol 16: 269-275.

694 Emsley, P., and Cowtan, K. (2004) Coot: model-building tools for molecular graphics. Acta 695 Crystallogr D Biol Crystallogr 60: 2126-2132.

696 Ettoumi, B., Guesmi, A., Brusetti, L., Borin, S., Najjari, A., Boudabous, A., and Cherif, A. (2013)

697 Microdiversity of deep-sea Bacillales isolated from Tyrrhenian sea sediments as revealed by ARISA, 698 16S rRNA gene sequencing and BOX-PCR fingerprinting. Microbes Environ 28: 361-369.

699 Gotsche, S., and Dahl, M.K. (1995) Purification and characterization of the phospho-alpha-(1,1)700 glucosidase (TreA) of Bacillus subtilis 168. J Bacteriol 177: 2721-2726.

701 Gouesbet, G., Jebbar, M., Talibart, R., Bernard, T., and Blanco, C. (1994) Pipecolic acid is an 702 osmoprotectant for Escherichia coli taken up by the general osmoporters ProU and ProP. 703 Microbiology 140 2415-2422.

704 Guerout-Fleury, A.M., Shazand, K., Frandsen, N., and Stragier, P. (1995) Antibiotic-resistance 705 cassettes for Bacillus subtilis. Gene 167: 335-336.

706 Harwood, C.R., and Archibald, A.R. (1990) Growth, maintenance and general techniques. In 707 Molecular biological methods for Bacillus. Harwood, C.R., and Cutting, S.M. (eds). Chichester: John 708 Wiley \& Sons, pp. 1-26.

709 Hoffmann, T., and Bremer, E. (2011) Protection of Bacillus subtilis against cold stress via compatible710 solute acquisition. J Bacteriol 193: 1552-1562.

711 Hoffmann, T., Wensing, A., Brosius, M., Steil, L., Völker, U., and Bremer, E. (2013) Osmotic control 712 of opuA expression in Bacillus subtilis and its modulation in response to intracellular glycine betaine 713 and proline pools. J Bacteriol 195: 510-522. 
714 Holtmann, G., and Bremer, E. (2004) Thermoprotection of Bacillus subtilis by exogenously provided

715 glycine betaine and structurally related compatible solutes: involvement of Opu transporters. $J$ 716 Bacteriol 186: 1683-1693.

717 Horn, C., Sohn-Bösser, L., Breed, J., Welte, W., Schmitt, L., and Bremer, E. (2006) Molecular 718 determinants for substrate specificity of the ligand-binding protein OpuAC from Bacillus subtilis for 719 the compatible solutes glycine betaine and proline betaine. J Mol Biol 357: 592-606.

720 Housecroft, C.E., and Sharp, A.G. (2008) Inorganic Chemistry. Essex, England: Pearson Education 721 Limited.

722 Ignatova, Z., and Gierasch, L.M. (2006) Inhibition of protein aggregation in vitro and in vivo by a 723 natural osmoprotectant. Proc Natl Acad Sci U S A 103: 13357-13361.

724 Jackson-Atogi, R., Sinha, P.K., and Rösgen, J. (2013) Distinctive solvation patterns make renal 725 osmolytes diverse. Biophys $J$ 105: 2166-2174.

726 Jaenicke, R. (1990) Protein structure and function at low temperatures. Philos T Roy Soc B 326: 535727553.

728 Kappes, R.M., and Bremer, E. (1998) Response of Bacillus subtilis to high osmolarity: uptake of 729 carnitine, crotonobetaine and butyrobetaine via the ABC transport system OpuC. Microbiology 144: $730 \quad 83-90$.

731 Kappes, R.M., Kempf, B., and Bremer, E. (1996) Three transport systems for the osmoprotectant 732 glycine betaine operate in Bacillus subtilis: characterization of OpuD. J Bacteriol 178: 5071-5079.

733 Kappes, R.M., Kempf, B., Kneip, S., Boch, J., Gade, J., Meier-Wagner, J., and Bremer, E. (1999) Two 734 evolutionarily closely related ABC transporters mediate the uptake of choline for synthesis of the 735 osmoprotectant glycine betaine in Bacillus subtilis. Mol Microbiol 32: 203-216.

736 Karsten, U., Wiencke, C., and Kirst, G.O. (1992) Dimethlysulfoniopropionate (DMSP) accumulation 737 in green macroalgae from polar to temperate regions: interactive effects of lioght versus salinity and 738 light versus temperature. Polar Biology 12: 603-607.

739 Karsten, U., Kück, K., Vogt, C., and Kirst, G.O. (1996) Dimethlysulfonoipropionate production in 740 phototrophic organisms and its physiological function as a cryoprotectant. In Biological and 741 Environmental Chemistry of DMSP and related Sulfonium Compounds. Kiene, R.P., Visscher, P.T., 742 Keller, M.D., and Kirst, G.O. (eds): Springer, pp. 143-153.

743 Kempf, B., and Bremer, E. (1995) OpuA, an osmotically regulated binding protein-dependent 744 transport system for the osmoprotectant glycine betaine in Bacillus subtilis. J Biol Chem 270: 1670174516713.

746 Kempf, B., and Bremer, E. (1998) Uptake and synthesis of compatible solutes as microbial stress 747 responses to high osmolality environments. Arch Microbiol 170: 319-330.

748 Kiene, R.P., Williams, L.P.H., and Walker, J.E. (1998) Seawater micrroganisms have a high affinity 749 glycine betaine uptake system which also recognizes dimethylsulfoniopropionate. Aquat Microb Ecol 750 15: $39-51$. 
751 Kiene, R.P., Linn, L.J., and Bruton, J.A. (2000) New and important roles for DMSP in marine 752 microbial communities. J Sea Res 43: 209-224.

753 Kohlstedt, M., Sappa, P.K., Meyer, H., Maass, S., Zaprasis, A., Hoffmann, T. et al. (2014) Adaptation 754 of Bacillus subtilis carbon core metabolism to simultaneous nutrient limitation and osmotic challenge: 755 a multi-omics perspective. Environ Microbiol 16: 1898-1917.

756 Levine, N.M., Varaljay, V.A., Toole, D.A., Dacey, J.W., Doney, S.C., and Moran, M.A. (2012)

757 Environmental, biochemical and genetic drivers of DMSP degradation and DMS production in the 758 Sargasso Sea. Environ Microbiol 14: 1210-1223.

759 Li, C.Y., Wei, T.D., Zhang, S.H., Chen, X.L., Gao, X., Wang, P. et al. (2014) Molecular insight into 760 bacterial cleavage of oceanic dimethylsulfoniopropionate into dimethyl sulfide. Proc Natl Acad Sci U 761 S A 111: 1026-1031.

762 Lippert, K., and Galinski, E.A. (1992) Enzyme stabilization by ectoine-type compatible solutes: 763 protection against heating, freezing and drying. Appl Microbial Biotechnol 37: 61-65.

764 Logan, N., and De Vos, P. (2009) Bacillus. In Bergey's Manual of Systematic Bacteriology. De Vos, 765 P., Garrity, G.M., Jones, D., Krieg, N.R., Ludwig, W., Rainey, F.R. et al. (eds). Heidelberg: Springer, 766 pp. 21-128.

767 Manzanera, M., Garcia de Castro, A., Tondervik, A., Rayner-Brandes, M., Strom, A.R., and 768 Tunnacliffe, A. (2002) Hydroxyectoine is superior to trehalose for anhydrobiotic engineering of 769 Pseudomonas putida KT2440. Appl Environ Microbiol 68: 4328-4333.

770 Miller, J.H. (1972) Experiments in molecular genetics. Cold Spring Harbor New York: Cold Spring 771 Harbor Laboratory.

772 Miller, T.R., Hnilicka, K., Dziedzic, A., Desplats, P., and Belas, R. (2004) Chemotaxis of Silicibacter 773 sp. strain TM1040 toward dinoflagellate products. Appl Environ Microbiol 70: 4692-4701.

774 Miranda, C.A., Martins, O.B., and Clementino, M.M. (2008) Species-level identification of Bacillus 775 strains isolates from marine sediments by conventional biochemical, 16S rRNA gene sequencing and 776 inter-tRNA gene sequence lengths analysis. Antonie Van Leeuwenhoek 93: 297-304.

777 Moran, M.A., Reisch, C.R., Kiene, R.P., and Whitman, W.B. (2012) Genomic insights into bacterial 778 DMSP transformations. Ann Rev Mar Sci 4: 523-542.

779 Murdock, L., Burke, T., Coumoundouros, C., Culham, D.E., Deutch, C.E., Ellinger, J. et al. (2014) 780 Analysis of strains lacking known osmolyte accumulation mechanisms reveals contributions of 781 osmolytes and transporters to protection against abiotic stress. Appl Environ Microbiol 80: 5366-5378. 782 Murshudov, G.N., Vagin, A.A., and Dodson, E.J. (1997) Refinement of macromolecular structures by 783 the maximum-likelihood method. Acta Crystallogr D Biol Crystallogr 53: 240-255.

784 Nishiguchi, M.K., and Somero, G.N. (1992) Temperature-dependence and concentration-dependence 785 of compatibility of the organic osmolyte beta-dimethylsulfoniopropionate. Cryobiology 29: 118-124. 
786 Nordberg, H., Cantor, M., Dusheyko, S., Hua, S., Poliakov, A., Shabalov, I. et al. (2013) The genome 787 portal of the Department of Energy Joint Genome Institute: 2014 updates. Nucleic Acids Res 42: D26788 D31.

789 Otte, M.L., Wilson, G., Morris, J.T., and Moran, B.M. (2004) Dimethylsulphoniopropionate (DMSP) 790 and related compounds in higher plants. $J$ Exp Bot 55: 1919-1925.

791 Pichereau, V., Pocard, J.A., Hamelin, J., Blanco, C., and Bernard, T. (1998) Differential effects of 792 dimethylsulfoniopropionate, dimethylsulfonioacetate, and other S-methylated compounds on the 793 growth of Sinorhizobium meliloti at low and high osmolarities. Appl Environ Microbiol 64: 14207941429.

795 Reisch, C.R., Moran, M.A., and Whitman, W.B. (2011) Bacterial catabolism of 796 dimethylsulfoniopropionate (DMSP). Front Microbiol 2: 172.

797 Rinta-Kanto, J.M., Sun, S., Sharma, S., Kiene, R.P., and Moran, M.A. (2012) Bacterial community 798 transcription patterns during a marine phytoplankton bloom. Environ Microbiol 14: 228-239.

799 Rinta-Kanto, J.M., Burgmann, H., Gifford, S.M., Sun, S., Sharma, S., del Valle, D.A. et al. (2011)

800 Analysis of sulfur-related transcription by Roseobacter communities using a taxon-specific functional 801 gene microarray. Environ Microbiol 13: 453-467.

802 Roeßler, M., and Müller, V. (2001) Osmoadaptation in bacteria and archaea: common principles and 803 differences. Env Microbiol Rep 3: 743-754.

804 Siefert, J.L., Larios-Sanz, M., Nakamura, L.K., Slepecky, R.A., Paul, J.H., Moore, E.R. et al. (2000)

805 Phylogeny of marine Bacillus isolates from the gulf of Mexico. Current Microbiol 41: 84-88.

806 Smith, J.L., Goldberg, J.M., and Grossman, A.D. (2014) Complete genome sequences of Bacillus

807 subtilis subsp. subtilis laboratory strains JH642 (AG174) and AG1839. Genome Announc 2: e00663-

80800614.

809 Smits, S.H., Höing, M., Lecher, J., Jebbar, M., Schmitt, L., and Bremer, E. (2008) The compatible-

810 solute-binding protein OpuAC from Bacillus subtilis: ligand binding, site-directed mutagenesis, and 811 crystallographic studies. J Bacteriol 190: 5663-5671.

812 Stefels, J. (2000) Physiological aspects of the production and conversion of DMSP in marine algae 813 and higher plants,. J Sea Res 43: 183-197.

814 Street, T.O., Bolen, D.W., and Rose, G.D. (2006) A molecular mechanism for osmolyte-induced 815 protein stability. Proc Natl Acad Sci US A 103: 13997-14002.

816 Street, T.O., Krukenberg, K.A., Rosgen, J., Bolen, D.W., and Agard, D.A. (2010) Osmolyte-induced 817 conformational changes in the Hsp90 molecular chaperone. Protein Sci 19: 57-65.

818 Sun, L., Curson, A.R., Todd, J.D., and Johnston, A.W.B. (2012) Diversity of DMSP transport in 819 marine bacteria, revealed by genetic analyses. Biogeochemsitry 110: 121-130.

820 Sunda, W., Kieber, D.J., Kiene, R.P., and Huntsman, S. (2002) An antioxidant function for DMSP and 821 DMS in marine algae. Nature 418: 317-320. 
822 Tanne, C., Golovina, E.A., Hoekstra, F.A., Meffert, A., and Galinski, E.A. (2014) Glass-forming

823 property of hydroxyectoine is the cause of its superior function as a dessication protectant. Front

824 Microbiol 5: 150.

825 Thompson, J.D., Plewniak, F., Thierry, J.C., and Poch, O. (2000) DbClustal: rapid and reliable global

826 multiple alignments of protein sequences detected by database searches. Nucleic Acids Res 28: 29198272926.

828 Todd, J.D., Kirkwood, M., Newton-Payne, S., and Johnston, A.W. (2012) DddW, a third DMSP lyase

829 in a model Roseobacter marine bacterium, Ruegeria pomeroyi DSS-3. ISME J 6: 223-226.

830 Todd, J.D., Curson, A.R., Nikolaidou-Katsaraidou, N., Brearley, C.A., Watmough, N.J., Chan, Y. et 831 al. (2010) Molecular dissection of bacterial acrylate catabolism - unexpected links with 832 dimethylsulfoniopropionate catabolism and dimethyl sulfide production. Environ Microbiol 12: 327833343.

834 Tschapek, B., Pittelkow, M., Sohn-Bösser, L., Holtmann, G., Smits, S.H., Gohlke, H. et al. (2011) 835 Arg149 is involved in switching the low affinity, open state of the binding protein AfProX into its 836 high affinity, closed state. J Mol Biol 411: 36-52.

837 Van Duyl, F.C., Gieskes, W.W.C., Kop, A.J., and Lewis, W.E. (1998) Biological control of short-term 838 variations in the concnetration of DMSP and DMS during a Phacocystis spring bloom. J Sea Res 40: $839 \quad 221-231$.

840 Vila-Costa, M., Simo, R., Harada, H., Gasol, J.M., Slezak, D., and Kiene, R.P. (2006) 841 Dimethylsulfoniopropionate uptake by marine phytoplankton. Science 314: 652-654.

842 von Blohn, C., Kempf, B., Kappes, R.M., and Bremer, E. (1997) Osmostress response in Bacillus 843 subtilis: characterization of a proline uptake system (OpuE) regulated by high osmolarity and the 844 alternative transcription factor sigma B. Mol Microbiol 25: 175-187.

845 Welsh, D.T. (2000) Ecological significance of compatible solute accumulation by micro-organisms: 846 from single cells to global climate. FEMS Microbiol Rev 24: 263-290.

847 Whatmore, A.M., Chudek, J.A., and Reed, R.H. (1990) The effects of osmotic upshock on the 848 intracellular solute pools of Bacillus subtilis. J Gen Microbiol 136: 2527-2535.

849 Widderich, N., Höppner, A., Pittelkow, M., Heider, J., Smits, S.H.J., and Bremer, E. (2014) 850 Biochemical properties of ectoine hydroxylases from extremophiles and their wider taxonomic 851 distribution among microorganisms. PloS one 9(4):e93809.

852 Wiegeshoff, F., and Marahiel, M.A. (2007) Characterization of a mutation in the acetolactate synthase 853 of Bacillus subtilis that causes a cold-sensitive phenotype. FEMS Microbiol Lett 272: 30-34.

854 Wolfe, G.V., Steinke, M., and Kirst, G.O. (1997) Grazing-activated chemical defence in a unicellular 855 marine alga. Nature 387: 894-897.

856 Wood, J.M. (2011) Bacterial osmoregulation: a paradigm for the study of cellular homeostasis. Annu 857 Rev Microbiol 65: 215-238. 
858 Yancey, P.H. (2005) Organic osmolytes as compatible, metabolic and counteracting cytoprotectants in 859 high osmolarity and other stresses. J Exp Biol 208: 2819-2830.

860 Yoch, D.C. (2002) Dimethylsulfoniopropionate: its sources, role in the marine food web, and 861 biological degradation to dimethylsulfide. Appl Environ Microbiol 68: 5804-5815.

862 Zaprasis, A., Brill, J., Thüring, M., Wünsche, G., Heun, M., Barzantny, H. et al. (2013)

863 Osmoprotection of Bacillus subtilis through import and proteolysis of proline-containing peptides.

864 Appl Environ Microbiol 79: 567-587.

865 Ziegler, C., Bremer, E., and Krämer, R. (2010) The BCCT family of carriers: from physiology to 866 crystal structure. Mol Microbiol 78: 13-34.

867

868 
869 Table 1. Repression of opuA expression by compatible solutes.

870

\begin{tabular}{lcc}
\hline Compatible solute & \multicolumn{2}{c}{ TreA activity $\left[\mathrm{U}\left(\mathrm{mg}\right.\right.$ protein $\left.\left.^{-1}\right)\right]$} \\
\cline { 2 - 3 } & without NaCl & $1.2 \mathrm{M} \mathrm{NaCl}$ \\
\hline none & $66 \pm 2$ & $561 \pm 35$ \\
Glycine betaine & $18 \pm 2$ & $88 \pm 3$ \\
Carnitine & $17 \pm 2$ & $102 \pm 4$ \\
DMSP & $16 \pm 1$ & $107 \pm 16$ \\
DMSeP & $19 \pm 1$ & $223 \pm 6$ \\
DMTeP & $30 \pm 1$ & $330 \pm 19$ \\
EMSP & $24 \pm 1$ & $313 \pm 3$ \\
DESP & $39 \pm 3$ & $381 \pm 9$ \\
IMSP & $25 \pm 3$ & $297 \pm 9$ \\
TMSP & $19 \pm 1$ & $224 \pm 10$ \\
& & \\
\hline
\end{tabular}

871

Cells of the opuA-treA reporter fusion strain MBB9 were grown either in SMM or in SMM

873 containing $1.2 \mathrm{M} \mathrm{NaCl}$ to mid-exponential growth phase $\left(\mathrm{OD}_{578 \mathrm{~nm}}\right.$ of about 1.5$)$ in the absence

874 or the presence of the indicated compounds and were then assayed for the activity for their

875 TreA reporter enzyme activity. The final concentration of the different compatible solutes

876 added to the growth media was $1 \mathrm{mM}$. The values shown are the averages of two

877 independently grown cultures, where each culture was assayed twice for phospho- $\alpha-(1,1)-$

878 glucosidase (TreA) activity. The data shown represent the error ranges of the enzyme assays.

879

880

881

882

883

884

885 
886 Table 2. Kinetic parameters for the uptake of DMSP and its derivatives

887 via the OpuC transport system of B. subtilis.

\begin{tabular}{lc}
$\begin{array}{c}\text { Compatible } \\
\text { solute }\end{array}$ & $\begin{array}{c}K_{i} \\
\left.(\mu \mathrm{M})^{\mathrm{a}}\right)\end{array}$ \\
\hline GB & - \\
DMSP & $39 \pm 7$ \\
DMSeP & $28 \pm 3$ \\
DMTeP & $18 \pm 2$ \\
EMSP & $29 \pm 4$ \\
DESP & $24 \pm 6$ \\
IMSP & $48 \pm 6$ \\
TMSP & $18 \pm 2$ \\
\hline
\end{tabular}

888

889 Cells of the B. subtilis $\mathrm{OpuC}^{+}$strain $\mathrm{SBB} 2$ were propagated at $37^{\circ} \mathrm{C}$ in $\mathrm{SMM}$ containing $0.4 \mathrm{M} \mathrm{NaCl}$ 890 to early-exponential growth phase ( $\mathrm{OD}_{578 \mathrm{~mm}}$ approximately 0.3$)$ and were then used for uptake studies 891 at $37^{\circ} \mathrm{C}$. For the various transport assays, the concentration of glycine betaine (GB) (spiked with [1$\left.892{ }^{14} \mathrm{C}\right]$ glycine betaine) was varied between $3 \mu \mathrm{M}$ and $100 \mu \mathrm{M}$, whereas the concentration of the various 893 inhibitors was kept constant at $150 \mu \mathrm{M}$. The data given for the inhibition constant $\left(K_{i}\right)$ for DMSP and 894 its derivatives are the averages of uptake studies conducted with two independently grown $B$. subtilis 895 cultures; the data shown represent the error ranges of the transport assays.

896

${ }^{\text {a) }}$ Transport assays with radiolabeled glycine betaine in the absence of an inhibitor were 897 conducted in parallel with each inhibition experiment. The average and standard deviation of the

898 kinetic data for glycine betaine uptake were $K_{m} 6 \pm 1 \mu \mathrm{M}$ and $V_{\max } 65 \pm 1 \mathrm{nmol} \mathrm{\operatorname {min } ^ { - 1 } \mathrm { mg } \text { of protein }}{ }^{-1}$. 899 900 901 902 
Table 3. B. subtilis strains used in this study.

\begin{tabular}{|c|c|c|}
\hline Strain & Relevant genotype $^{\text {a) }}$ & Origin/reference \\
\hline JH642 & $\operatorname{trpC2}$ pheAl & (Brehm et al., 1973) \\
\hline RMKB7 & JH642 $\Delta($ ориD::nео $) 2$ & (Kappes et al., 1996) \\
\hline SBB1 & JH642 $\Delta($ ориC::spс $) 3 \Delta($ ориD::nеo $) 2 \Delta($ opuB::ery $) 1$ & This study \\
\hline SBB2 & JH642 $\Delta($ opuA::tet $) 3 \Delta($ opuD::neo $) 2 \Delta($ opuB::ery $) 1$ & This study \\
\hline SBB4 & JH642 $\Delta($ opuC::spc $) 3 \Delta($ opuA::tet $) 3$ & This study \\
\hline TMB107 & JH642 $\Delta($ opuA::tet $) 3$ & This study \\
\hline TMB108 & $\mathrm{JH} 642 \Delta($ opuC::spc $) 3$ & This study \\
\hline TMB109 & JH642 $\Delta($ opuA::tet $) 3 \Delta($ opuD::nеo $) 2$ & This study \\
\hline TMB111 & JH642 $\Delta($ ориC::spc) $3 \Delta($ opuD::nеo $) 2$ & This study \\
\hline TMB116 & JH642 $\Delta($ opuB::ery $) 1$ & This study \\
\hline $\mathrm{MBB}^{\mathrm{b})}$ & JH642 amyE::[Ф(opuA-treA)1 cat] (treA::neo) & (Hoffmann et al., 2013) \\
\hline 168 & $\operatorname{trp} C 2$ & (Barbe et al., 2009) \\
\hline JGB23 & $168 \Delta($ opuA::erm $) 4 \Delta($ opuBD::tet $) 23$ opuC20::Tn10 (spc) & (Hoffmann and Bremer, 2011) \\
\hline JGB24 & $168 \Delta($ opuA::erm $) 4 \Delta($ opuBD::tet $) 23 \Delta($ opuD::neo $) 2$ & (Hoffmann and Bremer, 2011) \\
\hline JGB25 & $168 \Delta($ opuBD::tet $) 23$ ориC20::Tn10 (spc) $\Delta($ opuD::nеo $) 2$ & (Hoffmann and Bremer, 2011) \\
\hline
\end{tabular}

904

905

906

907

908

909

910

911

912

913

914

915

916

${ }^{a)}$ The OpuA, OpuB and OpuC transport systems are members oft the $\mathrm{ABC}$ transporter superfamily family and are multi-component systems. They are encoded by the opuA [ориAA-ориABориAC], ориB [ориBA-ориВB-ориBC-ориBD] and ориС [ориСA-ориCB-ориCС-ориCD] operons (Kempf and Bremer, 1995; Kappes et al., 1999). In the $\Delta($ opuA::tet) $3, \Delta($ opuB::ery) 1 and $\triangle($ ориC::spc $) 3$ mutant alleles, the entire coding sequences oft the $о р и A, о р и B$ and $о р и C$ operons has been removed and was replaced by the indicated antibiotic resistance cassettes.

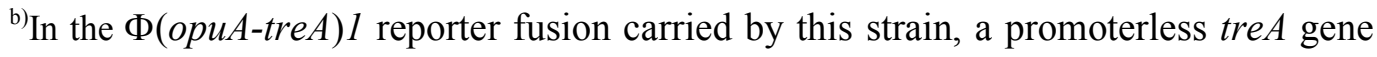
is placed under the transcriptional control of the osmotically regulated opuA promoter; the fusion junction between the truncated opuA material and tre $A$ is present within the $о p u A A$ gene of the opuA operon. The $\Phi($ opuA-tre $A) 1$ reporter construct was stably integrated via a double-homologous recombination event as a single copy into the $B$. subtilis genome within the non-essential amyE gene that is thereby rendered non-functional. 
917

918

919

920

921

922

923

924

925

926

927

928

929

930

931

932

933

934

935

936

937

938

939

940

941

942

943

944

945

946

947

948

949

950

951

952

953

954

955

956

957

958

\section{Legends to Figures}

Fig. 1. Chemical structures of DMSP and its natural and synthetic derivatives. DMSP: dimethylsulfoniopropionate; DMSeP: dimethylseleniopropionate; DMTeP: dimethyltelluriopropionate; EMSP: ethylmethylsulfoniopropionate; DESP: diethylsulfoniopropionate; MPSP: methylpropylsulfoniopropionate; IMSP: isopropylmethylsulfoniopropionate; TMSP: tetramethylenesulfoniopropionate; GB: glycine betaine; DMSA: dimethlysulfonioacetate.

Fig. 2. Protection of $B$. subtilis against salt, cold and heat challenges. (A) Cells of the B. subtilis strain JH642 were grown at $37^{\circ} \mathrm{C}$ in SMM containing $1.2 \mathrm{M} \mathrm{NaCl}$ either in the absence or the presence of the indicated compounds. (B) Cultures of the B. subtilis strain 168 were propagated at $13^{\circ} \mathrm{C}$ in SMM in the presence of the indicated compounds. (C) Cells of the B. subtilis strain JH642 strain were grown at $52^{\circ} \mathrm{C}$ in $\mathrm{SMM}$ in the presence or absence of the indicated compounds.

Fig. 3. Influence of DMSP and its derivatives on the cellular proline pool build up via de novo synthesis under osmotic stress conditions. Cells of the B. subtilis strain JH642 were grown in SMM containing $1.2 \mathrm{M} \mathrm{NaCl}$ in the absence or presence of various concentrations $(25 \mu \mathrm{M}-1000 \mu \mathrm{M})$ of the indicated compounds to mid-exponential phase $\left(\mathrm{OD}_{578 \mathrm{~nm}}\right.$ of about 1.6) and were then used the determination of their proline content by a colorimetric assay. The data shown are the results from two independently grown cultures and two technical replicas of the proline assay.

Fig. 4. Import of DMSP and its derivatives via the OpuA and OpuC ABC transport systems under osmotic stress. Cells of the B. subtilis strain JH642 and its mutant derivatives SBB1 (OpuA ${ }^{+}$), SBB2 $\left(\mathrm{OpuC}^{+}\right)$and SBB4 (OpuA $\left.{ }^{-} \mathrm{OpuC}^{-}\right)$were grown at $37^{\circ} \mathrm{C}$ in either the absence or the presence of the indicated compounds in $\mathrm{SMM}$ containing $1.2 \mathrm{M} \mathrm{NaCl}$; the growth-yield of the cultures was determined by measuring their $\mathrm{OD}_{578 \mathrm{~nm}}$ after $13 \mathrm{~h}$ of incubation. The values shown represent data from three independent biological experiments with two technical replicas for each experiment.

Fig. 5. Kinetic parameters of the OpuA and OpuC transporter system for DMSP. Michaelis-Menten kinetics of the uptake of $\left[1-{ }^{14} \mathrm{C}\right]$ glycine betaine (closed circles) and determination of the competitive inhibition of glycine betaine import by DMSP (open circles) via the OpuA (A) and OpuC (B) transport systems. The glycine betaine concentration in the uptake assays was varied as indicated, whereas the concentration of DMSP was kept constant; $1000 \mu \mathrm{M}$ for the transport assays conducted with the $\mathrm{OpuA}^{+}$strain SBB1 (A) and $150 \mu \mathrm{M}$ for those conducted with the OpuC ${ }^{+}$strain SBB2 (B).

Fig. 6. in silico models for the binding of DMSP by the OpuAC and OpuCC solute receptor proteins. Coordination of DMSA (dimethylsulfonioacetate) within the OpuAC ligand-binding site (OpuAC:DMSA); the structural data were taken from the PDB database (PDB accession code 3CHG). (B) in silico model for the OpuAC:DMSP complex. (C) Coordination of glycine betaine within the OpuCC ligand-binding site (OpuCC:GB); the structural data were taken from the PDB database (PDB accession code 3PPP). (D) in silico model for the OpuCC:DMSP complex. 

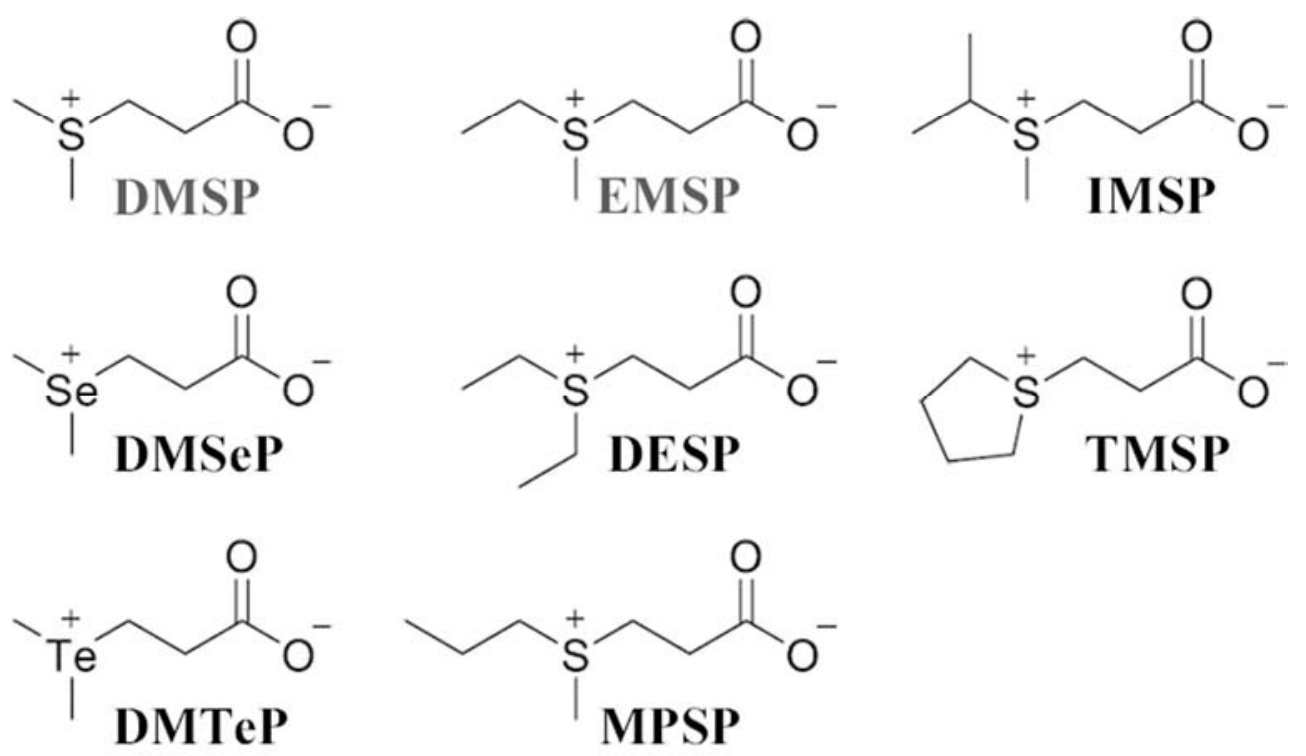<smiles>C[N+](C)(C)CC(=O)[O-]</smiles>

GB

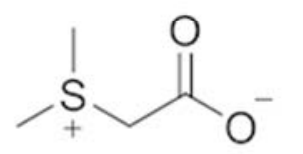

DMSA

$70 \times 60 \mathrm{~mm}(300 \times 300$ DPI) 

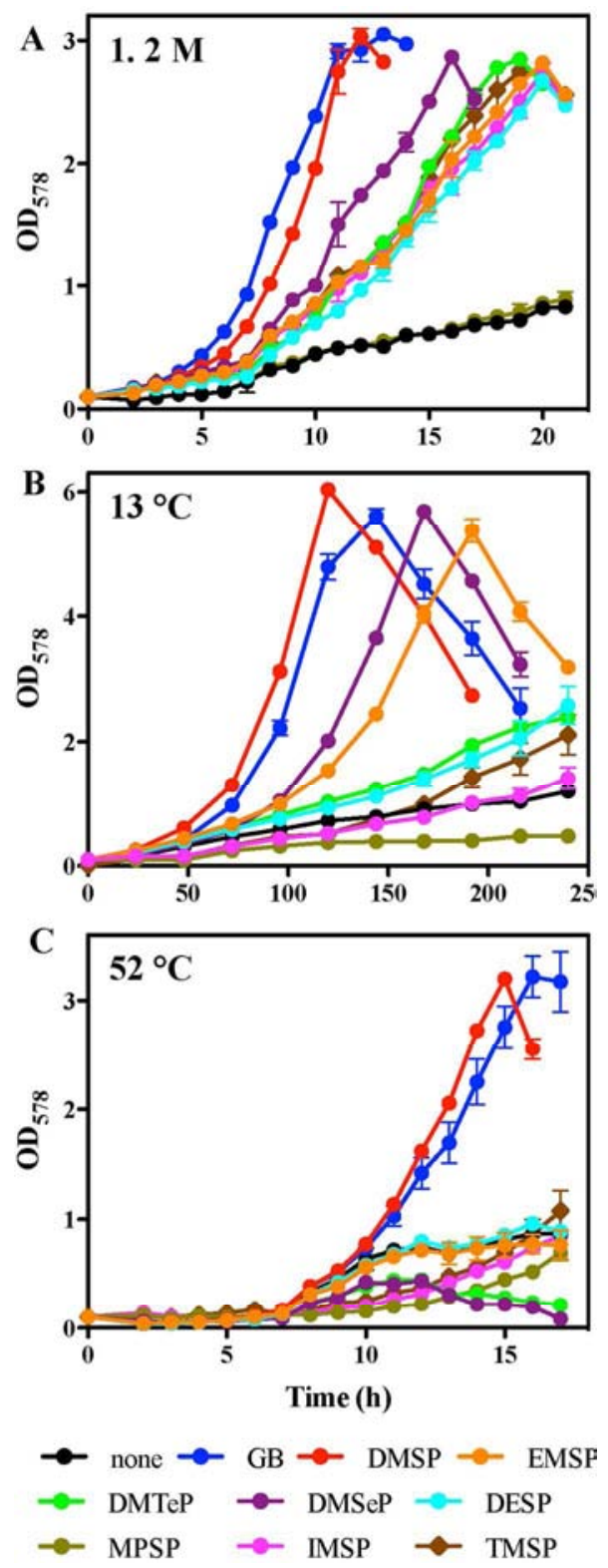

$70 \times 187 \mathrm{~mm}(300 \times 300 \mathrm{DPI})$ 

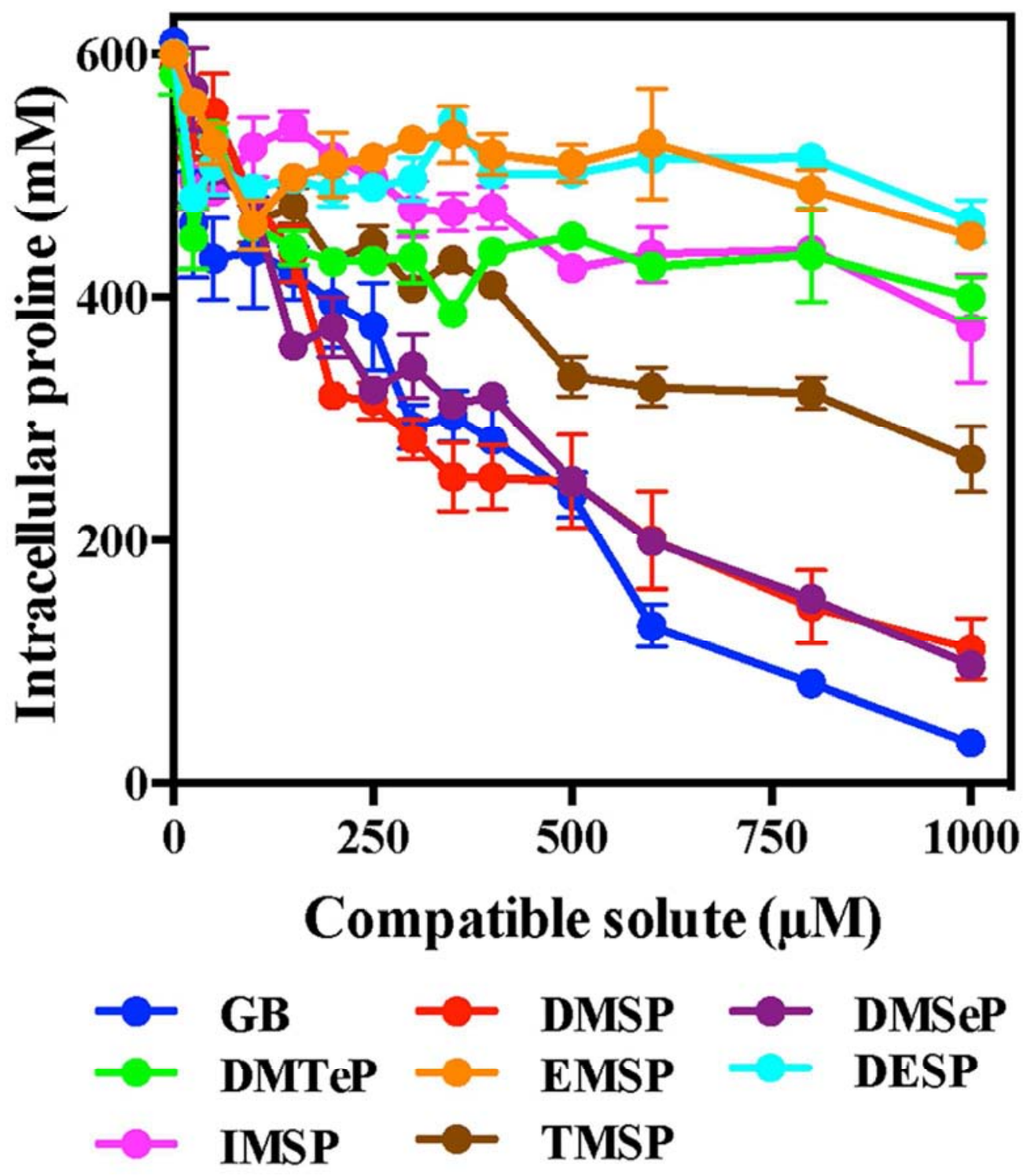

$70 \times 80 \mathrm{~mm}(300 \times 300$ DPI) 


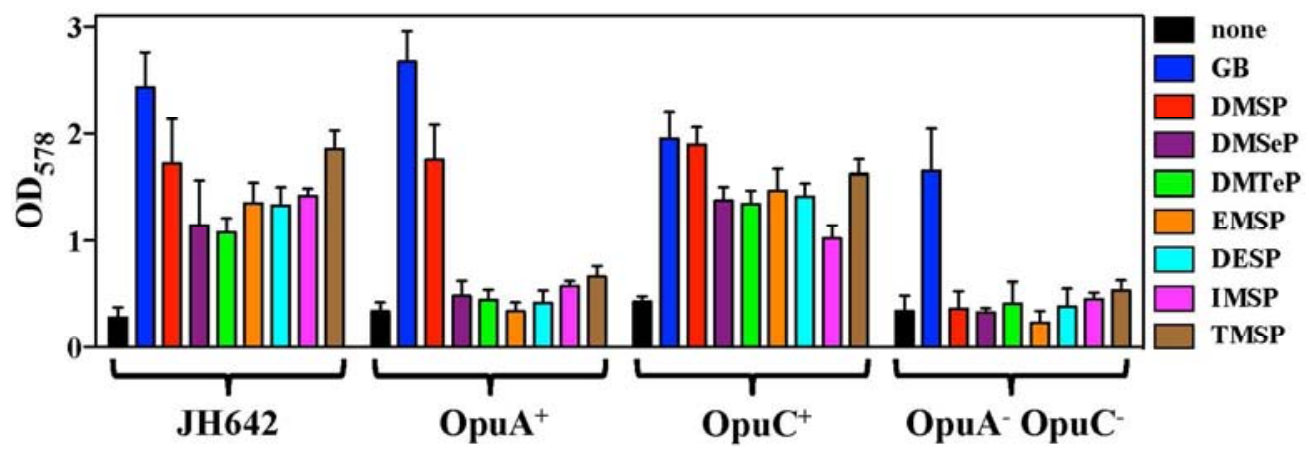

$148 \times 50 \mathrm{~mm}(300 \times 300 \mathrm{DPI})$ 

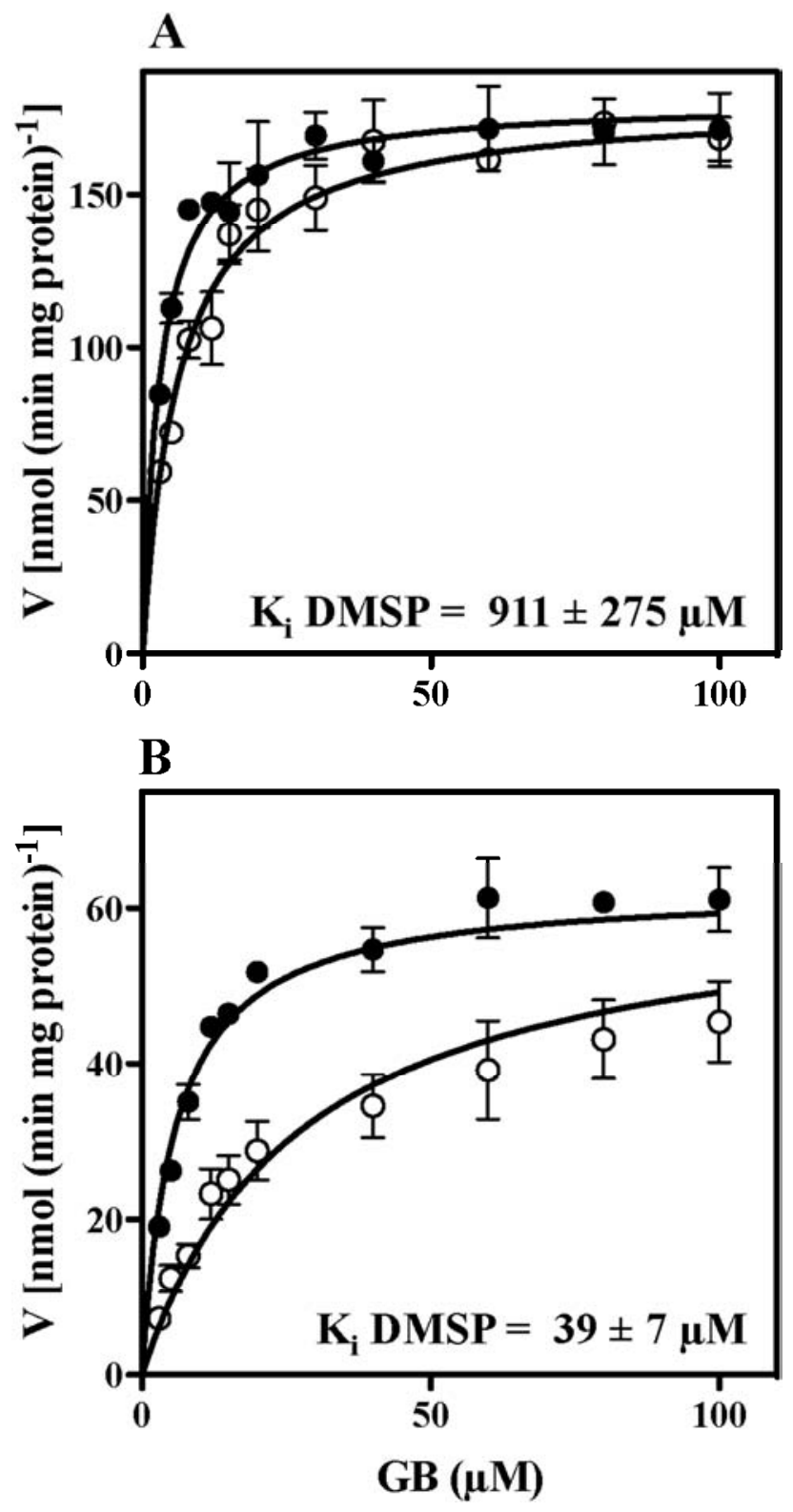

$72 \times 140 \mathrm{~mm}(300 \times 300$ DPI $)$ 

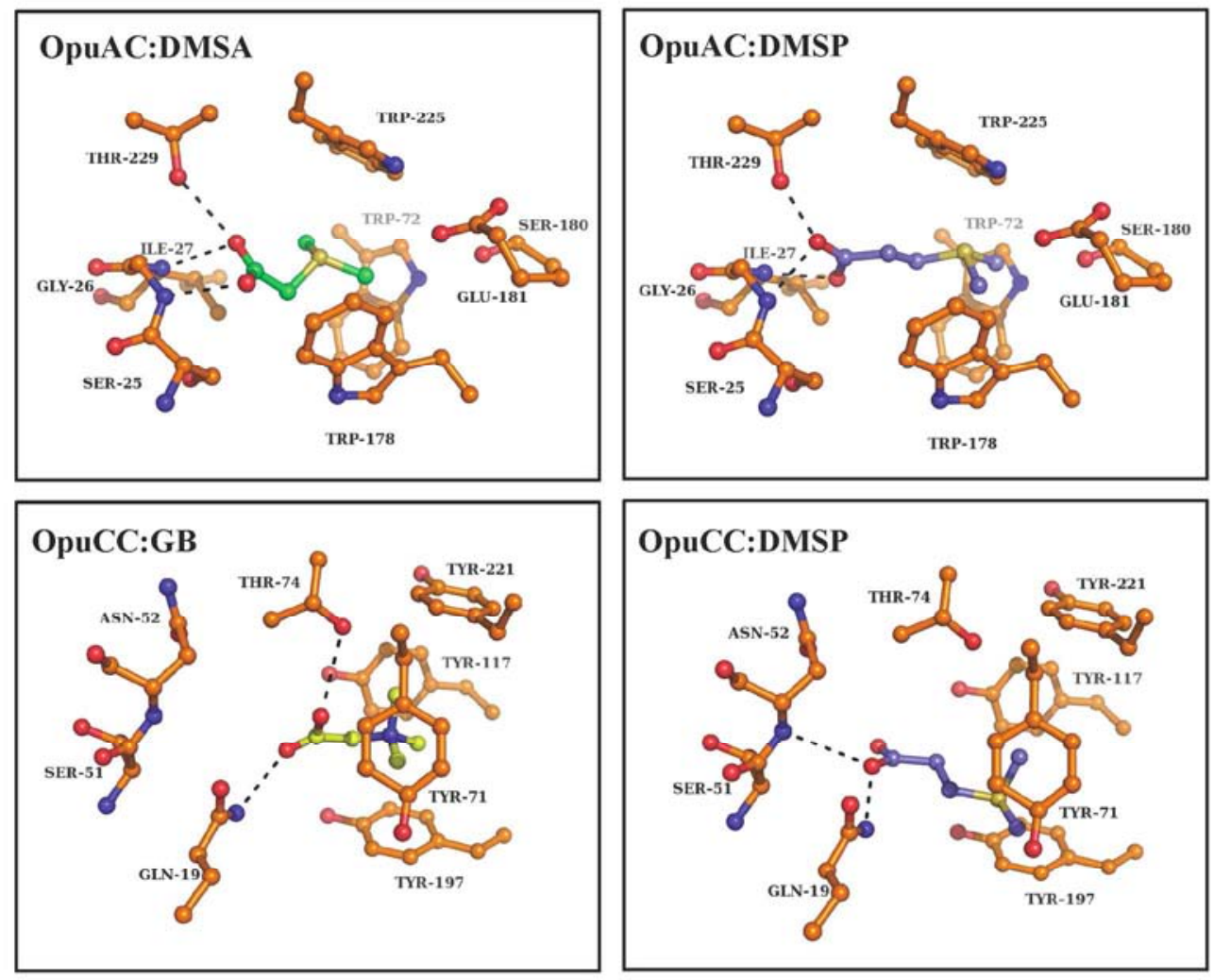

$160 \times 131 \mathrm{~mm}(300 \times 300$ DPI $)$ 